Ingrid Maier

\title{
Grigorij Kotošichin als Russischlehrer für zukünftige Übersetzer der schwedischen Krone?
}

Summary: This article deals with a manuscript kept in the Extranea collection of the Swedish State Archives in Stockholm. The manuscript overlaps with Alfabetum Rutenorum, a Russian textbook, printed in Stockholm by Peter van Selov around 1640. Both the imprint and the manuscript comprise the Cyrillic letters with their names in Cyrillic and in transliteration and the most central parts of Luther's small catechism. Moreover, the manuscript contains the shapes of the Cyrillic letters in the Chancery cursive style (skoropis') and a table with the Cyrillic numerals, from 1 to 1000000 . The manuscript - apparently intended as a new Russian textbook for future translators of Russian - was dated by the author to the $2^{\text {nd }}$ half of the 1660 s and attributed to G. Kotošichin, a former secretary of the Diplomatic Chancery who was living and working in Sweden from spring 1666 to his execution in the fall of 1667.

Keywords: Grigorij Kotošichin, hand-written Russian primer, Luther's catechism, Extranea collection in Stockholm, Swedish-Russian diplomatic relations.

\section{Hintergrund}

Grigorij Karpov Kotošichin (ca.1630-1667) - langjähriger Angestellter in Moskauer Kanzleien, u.a. am Gesandtschaftsamt (Posol'skij prikaz), der sich als Informator schwedischer Diplomaten ein Zubrot verdiente und dessen kurzes Leben schließlich unter dem Richterbeil ein schmähliches Ende fand - hat sich durch sein berühmtes Buch selbst ein Denkmal gesetzt: Kaum eine Einführung in die russische Geschichte oder Sprachgeschichte, die in den letzten 100 Jahren erschienen ist, lässt sein Werk (mit dem vom ersten Herausgeber, Ja. Berednikov, stammenden Titel „O России в царствование Алексея Михайловича“) unerwähnt. Der russische Text selbst wurde zwischen den Jahren 1840 und 2000 mehrfach heraus-

Prof. Dr. Ingrid Maier: Uppsala universitet, Institutionen för moderna språk, Box 636, 75/26 Uppsala, E-Mail: Ingrid.Maier@moderna.uu.se 
gegeben, wobei natürlich in unserem Zusammenhang insbesondere die philologisch vorbildliche Ausgabe von Anne Pennington hervorgehoben werden muss, auf die ich im Folgenden in erster Linie verweisen werde (Pennington 1980). ${ }^{1}$

Die schwedischen Akten über den ehemaligen russischen Kanzleischreiber machte der schwedische Historiker Harald Hjärne vor weit mehr als einem Jahrhundert bekannt, und zwar im ersten Heft von Historisk tidskrift (Hjärne 1881); dank der Vermittlung von Jakov Grot wurde der Inhalt von Hjärnes Artikel schon im Jahr darauf - stellenweise etwas verkürzt, an anderen Stellen leicht erweitert - auch russischen Lesern zugänglich (Grot 1882). Die erste Monographie über Kotošichins Leben und Werk erschien ebenfalls schon im vorletzten Jahrhundert (Markevič 1895); die meisten späteren Arbeiten stützen sich auch heute noch vor allem auf diese 120 Jahre alte Publikation. ${ }^{2}$ Hier kann vor allem der unterhaltsame populärwissenschaftliche Artikel von Vladislav Tarasov (1997) genannt werden (der ganz und gar ohne Literatur- und Quellenhinweise auskommt, aber andererseits auch keinen auffallenden Fehler enthält), die Einleitung $\mathrm{zu}$ der Textausgabe von G. A. Leont'eva (2000), die Monographie von H. Łaszkiewicz (2007) sowie die schon vor über zehn Jahren geschriebene Arbeit von A. V. Beljakov, die jedoch erst jetzt veröffentlicht wird (Beljakov, im Druck ${ }^{3}$ ). Dieser Forscher hatte schon für seine

1 Zwischen der ersten und der bisher letzten Ausgabe - Leont'eva 2000 - erschienen in Russland noch Editionen in den Jahren 1859 (2. Auflage), 1884 (3.), 1906 (4.); für bibliographische Angaben s. Pennington (1980, 762) und Łaszkiewicz (2007, 250-251). Außer den genannten separaten Ausgaben wurde Kotošichins Bericht auch zusammen mit anderen Texten in Sammelbänden herausgegeben, so z.B. leicht gekürzt, in ganzen 200000 Exemplaren (!), in der erstaunlichen Kombination mit einem Roman von Vasilij Šukšin über Stepan Razin, „Ja prišel dat’ vam volju“ (s. Buntašnyj vek 1983). - Neuerdings ist übrigens die englische Übersetzung des Buches von Benjamin Uroff im Internet frei zugänglich (Zugriff 24. Juni 2014): http://www.degruyter.com/ viewbooktoc/product/212901.

2 Insbesondere geht die Angabe von Kotošichins Geburtsjahr, „ca. 1630“, auf diese Arbeit zurück (Markevič 1895: 6-7), wobei eines der Argumente, die dabei herangezogen werden - die Bezeichnung von Kotošichin als „Kerl“ in einem (deutschsprachigen) Brief des schwedischen Diplomaten Adolf Ebers aus Moskau an den (noch unmündigen) König Karl XI. im Jahre 1663 - wohl ziemlich auf Sand gebaut ist. (Das Dokument befindet sich im schwedischen Reichsarchiv in Stockholm (im weiteren: RAS), Diplomatica Muscovitica 602, Brief vom 22. Juli 1663.) Das angegebene Geburtsjahr kann natürlich trotzdem ungefähr stimmen, wenn man bedenkt, dass Kotošichin frühestens ab 1645 in den Moskauer Behörden angestellt war und in den Jahren 1658-1661 mehrfach mit diplomatischen Aufträgen ins Ausland geschickt wurde, u.a. einmal nach Stockholm (Hjärne 1881: 70); s. auch den Originalbrief vom 7. August 1661, in dem Kotošichin ausdrücklich als gonec erwähnt wird: RAS, Diplomatica Muscovitica 618. (Als Schreiber konnte er schon mit ungefähr 12-15 Jahren angestellt werden; Markevič 1895: 7.)

3 An neuen Dokumenten stellt Beljakov (im Druck) einen Bericht von Michail Prokop'ev aus dem Russischen Staatsarchiv für ältere Akten vor (im weiteren: RGADA), in zwei fast gleichlautenden Schreiben. Prokop'ev wurde im Herbst 1665 mit einem Brief an den schwedischen König nach 
Dissertation (vgl. Beljakov 2001) das gesamte Archiv des Moskauer Gesandtschaftsamts während der Regierungszeit von Zar Aleksej Michajlovič durchforscht; er scheint dabei jedoch nur auf wenige Akten zu Kotošichin gestoßen zu sein, die vorher noch nicht bekannt waren.

Durch ein in diesem Zusammenhang neues Manuskript, das offenbar aus der Feder von Grigorij Kotošichin stammt und hier erstmals ausführlich vorgestellt wird, meine ich jedoch, endlich wieder einige neue Aspekte in die Diskussion bringen zu können.

\section{Eine kurze Anleitung zum Erlernen der russischen Sprache im Stockholmer Reichsarchiv}

In der Sammlung „Extranea“ des schwedischen Reichsarchivs ${ }^{4}$ gibt es ein Manuskript, das offenbar als Lehrmittel - eine Art „Einführung in die russische Sprache für schwedische Zielpersonen“ - gedacht war. (Der Einfachheit halber nenne ich es im weiteren manchmal „Russischkompendium“.) Es wurde erstmals in einer Arbeit über die frühe kirchliche Slavistik in Schweden erwähnt, da es unter anderem ein paar grundlegende Texte aus Luthers Katechismus enthält (Tarkiainen 1974: 77). In seinem Artikel stellte Tarkiainen einen Zusammenhang fest zwischen dem ältesten gedruckten „Lehrbuch“ für Russisch als Fremdsprache, Alfabetum Rutenorum (Stockholm bei Peter van Selov, ohne Angabe des Jahres, aber wahrscheinlich in den Jahren 1638-1644 entstanden), und dem genannten, ebenfalls undatierten Manuskript; er hatte jedoch keine Antwort auf die Frage, ob das Manuskript eine Vorbereitung für die gedruckte Broschüre darstellte oder ob - umgekehrt - der Druck primär war und das Manuskript eine partielle Abschrift. In meiner eigenen Arbeit (Maier 2012), die in erster Linie der gedruckten Broschüre Alfabetum Rutenorum (im weiteren manchmal verkürzt Alfabetum genannt) gewidmet war, habe ich die Stockholmer Handschrift auf die 2. Hälfte der 1660er Jahre datiert und dadurch eindeutig gezeigt, dass das Manuskript keine Vorarbeit für Alfabetum sein kann, sondern eine partielle Abschrift darstellen

Stockholm geschickt; in Narva nahm er mit dem dortigen Generalgouverneur, Jakob Johan Taube, in Sachen Kotošichin Kontakt auf. Über diese Kontakte und das „Versteckspiel“, das Taube mit den russischen Behörden anzettelte, sind wir aus Taubes Briefen an den schwedischen König bestens informiert (vgl. Hjärne 1881: 58-61); die russischen Dokumente über diese Kontakte waren dagegen bisher noch nicht bekannt (RGADA, F. 96, Op. 1, 1665, Nr. 6, Fol. 55-56).

4 RAS, Extranea 157:6, Mappe „Odaterade strödda handlingar“( ('undatierte vermischte Akten'). 
muss. Sowohl meine Datierung der Handschrift als auch viele weitere Argumente sprachen deutlich für Kotošichin als Anfertiger des handschriftlichen „Russischkompendiums“. ${ }^{5}$ Im vorliegenden Aufsatz möchte ich nun überzeugende Argumente für meine Zuweisung vortragen und auch erstmals einige Seiten der Handschrift im Druck vorstellen (s. Abb. 1-5). Die Zuweisung der aktuellen Handschrift zu Kotošichin trägt dann ihrerseits dazu bei, einige kleine Puzzlestücke zu unseren bisherigen Kenntnissen über ihren Verfasser hinzuzufügen.

\subsection{Beschreibung der Handschrift: materieller Zustand und Inhalt}

Die Handschrift besteht aus einer einzigen, zusammengehefteten Lage von acht Blatt mit den Maßen 227 x $167 \mathrm{~mm}$. Drei Seiten - das ganze erste Blatt und außerdem die letzte Seite (Fol. [8]v) - enthalten keinerlei Text, sondern nur einen leeren doppelten Rahmen (153 x 110 mm), in zwei Spalten aufgeteilt. Schon an dieser äußeren Form zeigt sich die Ähnlichkeit mit dem gedruckten „Russischlehrbuch“ Alfabetum, das jedoch den Doppelrahmen auf allen Seiten aufweist. ${ }^{6}$

Die erste Seite mit sprachlichem Inhalt ist Fol. [2]r (s. Abb. 1), auf der das kyrillische Alphabet in zwei Ausführungen aufgelistet wird, und zwar zuerst als „Versalien“, danach - in deutlich kleinerer Ausführung - als „Minuskeln“,7 wobei am Anfang beider Serien eine zusätzliche Initiale „a“ in roter Tinte angebracht ist (der Großbuchstabe in einer sehr künstlerischen Ausführung). Dabei

5 Zwischen meiner ersten Begegnung mit der Handschrift und deren Datierung und Zuweisung zu Kotošichin lagen einige Jahre. Zum Zeitpunkt der letzten Korrektur meines Aufsatzes in der Festschrift für Helmut Keipert hatte ich das Rätsel gerade gelöst, und ich konnte im letzten Moment noch eine kurze Anmerkung über den mutmaßlichen Verfertiger der Extranea-Handschrift einfügen, die auch in der genannten Arbeit eine - wenn auch nur untergeordnete - Rolle spielte; vgl. Maier 2012, 350, Anm. 41. (An der „weißrussischen“ Schreibweise des Namens, Katašichin, hatte ich keinen Anteil. Die einzigen mir bekannten Dokumente, in denen diese Schreibweise - neben einigen anderen - vorkommt, sind die beiden Berichte des russischen Kuriers Prokop'ev vom Nov. 1665 im RGADA; vgl. Anm. 3. In dem einzigen auf uns gekommenen Dokument, das er selbst mit seinem vollen, ursprünglichen Namen unterzeichnet hat - die Petition an den polnischen König aus dem Jahre 1664/65 - schrieb er „Григориі Котошихинъ“; s. Pennington 1980: 760.)

6 Vgl. die Abbildung der Titelseite in Maier 2012: 336. (Die Maße unterscheiden sich geringfügig: der Rahmen des Druckes ist ein paar Millimeter höher und breiter als der Rahmen in der Handschrift.)

7 Eine Unterscheidung in Versalien und Minuskeln gab es eigentlich nicht; die beiden Serien unterscheiden sich vor allem in der Größe, nicht in der Form. 


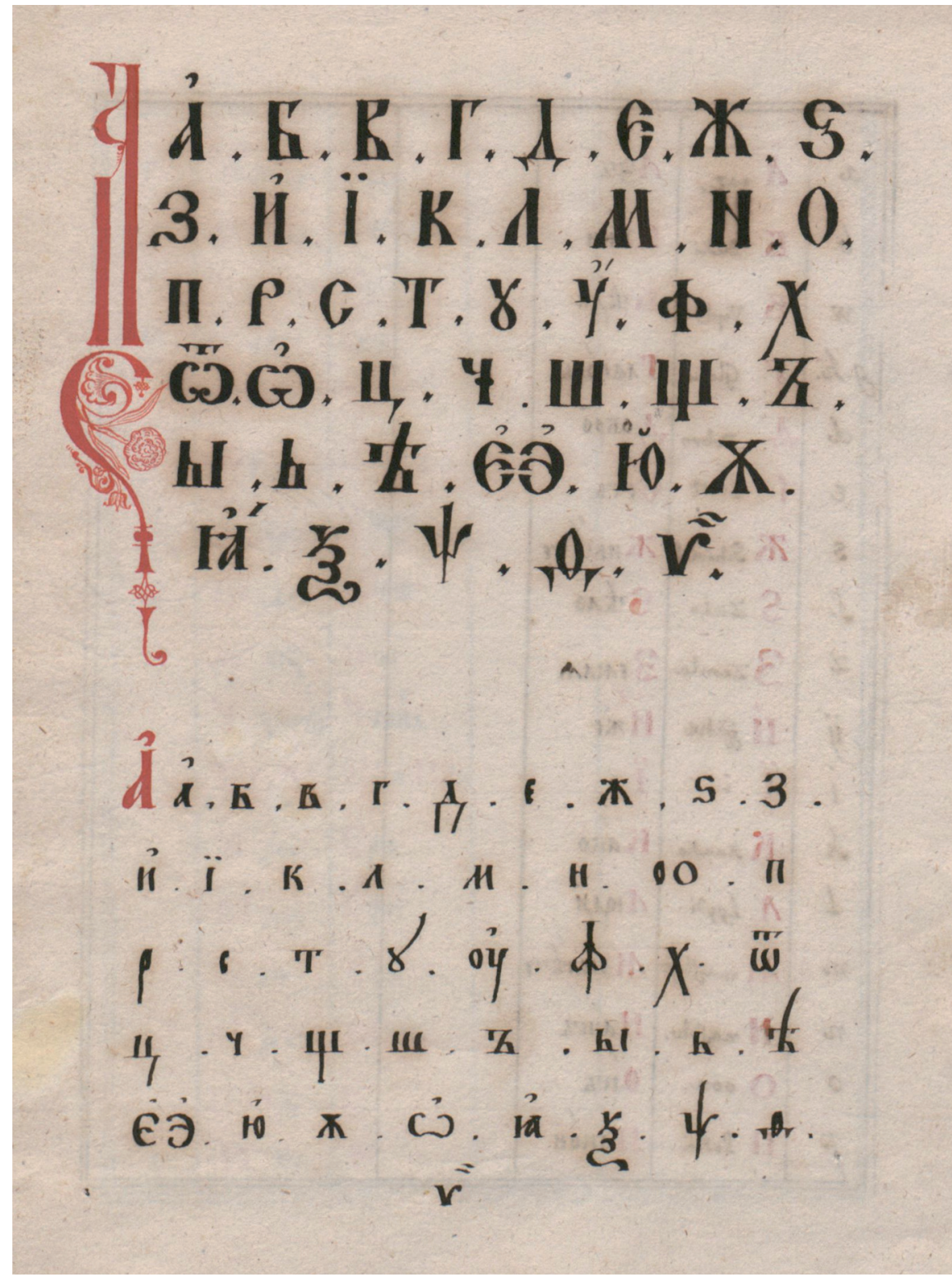

Abb. 1. Fol. [2]r: Die erste Textseite des Stockholmer Extranea-Manuskripts.

sind die beiden Serien weitgehend untereinander identisch, abgesehen von einigen minimalen Unterschieden: So enthalten beide Serien für das / $\mathrm{u} /$-Phonem das Graphem 〈8〉; daneben enthält die erste noch das 〈y〉, die zweite dagegen den 


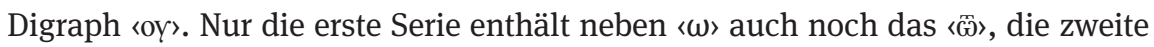
hat dafür zwei verschiedene 〈0〉-Grapheme, ein schmales und ein breiteres, das in der ersten fehlt. Außerdem ist die Reihenfolge der Grapheme 〈ш щ〉 in der zweiten Serie umgekehrt (« ш〉). Beide Serien enthalten - hinter dem jat' und dem 〈€〉Graphem - auch noch das moderne «э〉, was zu dieser Zeit in ostslavischen Fibeln noch nicht üblich war. ${ }^{8}$ In diesem Fall folgte der Verfertiger der Handschrift ganz einfach seiner Vorlage, der gedruckten Broschüre Alfabetum Rutenorum, wobei er sich natürlich an den ersten beiden Serien - den einzigen vollständigen Auflistungen in diesem Druck - orientiert haben muss. Der wichtigste Unterschied im Vergleich zu der gedruckten Vorlage ist das Fehlen von 〈A〉 in der Handschrift; entweder hat er es vergessen, oder er sah nicht ein, wozu neben einem «a〉 auch noch ein eigener $\langle A\rangle$-Buchstabe stehen sollte. (Schon in der gedruckten Vorlage, Alfabetum, standen 〈 $\mathrm{a}\rangle$ und 〈A〉 als eine Art Varianten nebeneinander, mit nur einem Namen für beide Grapheme, „Jaa“.) Die Auflistung der Buchstaben in den Formen der Kanzleikursive - skoropis’ - einige Seiten später deutet, wie wir sehen werden, eher auf die zweite Erklärung hin, denn es gibt keinen Punkt, oder gar „...“, zwischen den ra-ähnlichen und den A-ähnlichen Zeichen, wie in allen Fällen, in denen wirklich zwei verschiedene Grapheme in derselben Zeile stehen (s. Abb. 2-3).

Auf den folgenden drei Seiten (Fol. [2]v, [3]r-v) befindet sich noch einmal das kyrillische Alphabet. Diese Seiten sind jeweils in fünf Spalten aufgeteilt (gegenüber vier in Alfabetum). Die zweite Spalte enthält die kyrillischen Buchstaben nun in roter Farbe - entsprechend der Auflistung auf der ersten Seite; daneben steht - in derselben Spalte, in schwarz - in den meisten Fällen der Name des

8 Nach Šustova 2010: 477 wurde das «э»-Graphem nur in einem einzigen gedruckten Moskauer ABC-Buch des 17. Jahrhunderts erwähnt, und zwar im Bukvar' jazyka slavenska (gedruckt am 28. Sept. 1667). Das vollständigere der beiden erhaltenen Exemplare dieses Druckes wird in der Universitätsbibliothek von Uppsala aufbewahrt (Sign. Slav. 62) und enthält handschriftliche Zusätze von Johan Gabriel Sparwenfeld, in erster Linie - aber nicht nur - auf interfoliierten Blättern (s. Birgegård 1992: 46-52, insbesondere die Illustration auf S. 47); übrigens stimmt Sparwenfelds Auflistung der Buchstaben so weitgehend mit der in Alfabetum Rutenorum überein, dass die Annahme eines direkten Einflusses nahe liegt. Die russische Forscherin Ju. Šustova hatte den Druck jedoch offenbar nicht im Original, sondern auf einem Mikrofilm untersucht. Dabei war ihr entgangen, dass der obere Teil von Fol. 23v (nach der modernen Foliierung der Bibliothek) zu den handschriftlichen, später eingeklebten Ergänzungen und nicht zum ursprünglichen Druck gehört; auf Fol. 33r wurden ebenfalls einige Grapheme - darunter 〈€〉 und 〈э〉 - von Hand hinzugefügt. Das 〈э〉-Graphem wurde somit im ganzen 17. Jahrhundert in keinem einzigen Moskauer ABC-Buch in das Alphabet aufgenommen; es kam zu dieser Zeit ausschließlich in einigen im Ausland gedruckten Russischlehrmitteln vor. (Vgl. hierzu neuerdings auch Uspenskij, 2014: 30-31, Anm. 22. - Zur Geschichte des 〈э〉-Graphems in altrussischen Notenhandschriften s. Uspenskij 2013.) 
entsprechenden Buchstaben in lateinischer Transkription. Die dritte Spalte nennt dieselben Namen in kyrillischer Schrift, wobei wieder ein paar Besonderheiten zu nennen sind: 〈̈̈〉 und 〈Ю〉 haben keine „Namen“, sondern es wird in der Namensspalte einfach der entsprechende Buchstabe selbst noch einmal wiederholt; bei 〈оу〉 steht als Name „У“, bei 〈b〉 „натъ“ (sic! mit $ъ$ !); 〈€〉 und 〈э〉 - die offenbar als Varianten betrachtet werden - heißen beide „є“. Bemerkenswert ist weiterhin, dass «ш〉 und 〈щ〉 nebeneinander stehen (nicht untereinander) und dass als „Namen“ für 〈ш щ〉 „ща ша“ (in dieser Reihenfolge!) angegeben sind. Als „Name“ von 〈A〉 ist „H“ genannt.

In der allerersten Spalte, ganz links, werden für viele der kyrillischen Buchstaben - aber bei weitem nicht für alle - lateinische Äquivalente aufgeführt, z. B. für die ersten vier Buchstaben des kyrillischen Alphabets „a, b, w, g h“. (Die lateinischen Buchstaben „g“ und „h“ stehen dabei nebeneinander, entsprechend der Anordnung im gedruckten Alfabetum; sie werden also beide als mögliche Äquivalente $\mathrm{zu}\langle\Gamma\rangle$ betrachtet - übrigens wird in beiden Lehrmitteln „h“ als Transkription auch für 〈 $\mathrm{X}$ 〉 angegeben). Einige Unterschiede $\mathrm{zu}$ Alfabetum gibt es jedoch auch hier: die lateinische Entsprechung $\mathrm{zu}$ 〈3〉 ist in der Handschrift „, Z“, nicht „S“, wie in der gedruckten Broschüre; 〈и〉 wird jetzt durch „ij“ (oder „:̈“) wiedergegeben, ¿ì dagegen durch „i“ (in Alfabetum war als Entsprechung zu beiden Graphemen in der ersten Spalte „i“ genannt); bei 〈A/ra > hat Alfabetum „ä”, die Handschrift dagegen „a“. ${ }^{9}$ Die erstgenannte Abweichung scheint mir relevant zu sein im Kontext der Diskussion zum Autor der Handschrift: Für Kotošichin der während seines Aufenthaltes in Polen Polnisch gelernt hatte - ist es natürlich

9 Der Autor von Alfabetum dachte wohl an russische Wörter wie nять und empfand hier einen Unterschied zu einem „gewöhnlichen“ [a]-Laut, während der Verfertiger der Handschrift eher an Formen wiе лягу, мясо usw. gedacht haben kann. Außerdem existierte wohl in der Vorstellungswelt unseres (russischen!) Abschreibers kein „ä“ - dessen phonetische Entsprechung, [ع], ja weder im Russischen noch im Polnischen den Status eines Phonems hat - als eine eigene psychologische Einheit, für den (schwedischen!) Autor von Alfabetum dagegen selbstverständlich durchaus, da im Schwedischen /e/ und / $\varepsilon$ / verschiedene Phoneme sind (letzteres mit den Allophonen [ع] und [æ], jedenfalls im heutigen Schwedisch). Völlig konsequent gibt dann auch der russische Verfertiger der Handschrift die Namen der Buchstaben Земля und Ять in seiner Transkription als „Zemla, jaat“ wieder, während der schwedische Autor von Alfabetum diese mit „Zemlä, Jäät“ transkribiert hatte, d.h. der Autor der Vorlage hatte berücksichtigt, dass das russische /a/ in Positionen hinter - und besonders zwischen - palatalisierten Konsonanten etwas anders, nämlich geschlossener, ausgesprochen wird als in anderen Positionen; vgl. z.B. „Glahol, Kaako, Naasch“ (ebenfalls in Alfabetum; dagegen enthält die Handschrift im letzteren Fall „Nasch“ deren Verfasser war anscheinend bereit, in der betonten offenen Silbe ка - in Како - einen langen Vokal anzuerkennen, nicht jedoch in der geschlossenen von Haw). Es scheint, dass der Autor von Alfabetum in erster Linie phonetisch dachte, der Verfertiger der Handschrift dagegen eher phonologisch. 
naheliegender, ausgehend von der Aussprache des polnischen $\langle\mathrm{Z}\rangle$-Graphems als [z], in der Transkriptions- bzw. Aussprachespalte eben dieses Zeichen anzugeben; bei einem Schweden wäre das sehr überraschend gewesen, da ein stimmhaftes [z] in seiner Sprache nicht existiert. Für viele Grapheme gibt es jedoch schon in der gedruckten Broschüre überhaupt keine Entsprechung in dieser ersten Spalte, und

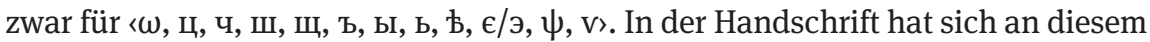
Zustand nicht viel geändert, aber immerhin finden wir hier für $\langle\bar{\omega}\rangle^{10}$ in der linken Spalte nun doch eine Entsprechung, nämlich „å“ (mit der Namensform „ååt“ in der zweiten Spalte). Das ist völlig korrekt, denn das schwedische 〈å〉 wird immer als [o] ausgesprochen - im Gegensatz zum schwedischen 〈0〉, das nur relativ selten als [o] ausgesprochen wird, viel häufiger dagegen als [u]. ${ }^{11}$ Wir können aus diesem Zusatz wohl den Schluss ziehen, dass der Verfertiger der Handschrift über eine gewisse Vorstellung vom Verhältnis zwischen Lauten und Graphemen im Schwedischen verfügte.

In der gedruckten Broschüre gibt es danach noch eine weitere Spalte, die in den meisten Fällen leer blieb, aber in einem Viertel aller Zeilen - genauer gesagt in zehn von vierzig Fällen - Anweisungen (in Schwedisch) für die Aussprache gewisser Buchstaben enthält. ${ }^{12}$ Der Verfertiger der Handschrift hat hier nicht nur eine Spalte eingerichtet (wie in Alfabetum), sondern zwei, die aber beide leer geblieben sind. Ich nehme selbstverständlich an, dass er einen Plan hatte, wie diese beiden Spalten später ausgefüllt werden sollten (vielleicht von einem schwedischsprachigen Kollegen?).

Die folgenden Seiten (Fol. [4]r-v; s. Abb. 2-3) enthalten die Buchstabenformen der russischen Kanzleikursive (skoropis'), wobei jeder Buchstabe mit möglichst vielen Varianten vertreten ist. ${ }^{13}$ Die ersten drei Buchstaben des Alphabets $\langle a, \sigma, \mathrm{B}\rangle$ (und, ein bisschen überraschend, $\langle\theta\rangle$ ) - füllen dabei eine ganze Zeile aus, die übrigen eine halbe; im letztgenannten Fall steht zwischen den beiden dis-

10 Ein $\langle\omega\rangle$ - ohne das $\langle\mathrm{T}\rangle$ als Superscript - gibt es nicht in der Handschrift. (Die Vorlage, Alfabetum, enthielt an dieser Stelle einen offenbaren Fehler: Das « $\omega$ » wurde hier zweimal genannt, einmal transkribiert als „ååt“, einmal als „„åa“, was sicher bedeutet, dass in der handschriftlichen

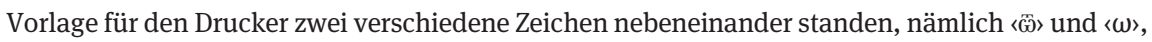
im Druck aber zweimal dieselbe Type gesetzt wurde.)

11 Als Äquivalent zum kyrillischen «o〉 wurde sowohl im Druck als auch in der Handschrift in der schwedischen Spalte „o“ genannt.

12 Für eine Diskussion einiger dieser „Aussprachehilfen“ $s$. Maier 2012: 340-341.

13 Das nach Tönnies Fenne (historisch korrekt T. Fonne; s. Hendriks 2014) benannte niederdeutsch-russische Gesprächsbuch, das im Jahre 1607 in Pleskau hergestellt wurde, enthält allerdings für die meisten Buchstaben noch mehr Varianten, nämlich für jedes Graphem eine ganze Zeile (vgl. Fenne 1961: 561-564); diese Aufstellung nimmt daher ganze vier Seiten in Anspruch, im Vergleich zu den knapp zwei Seiten im Extranea-Manuskript. 


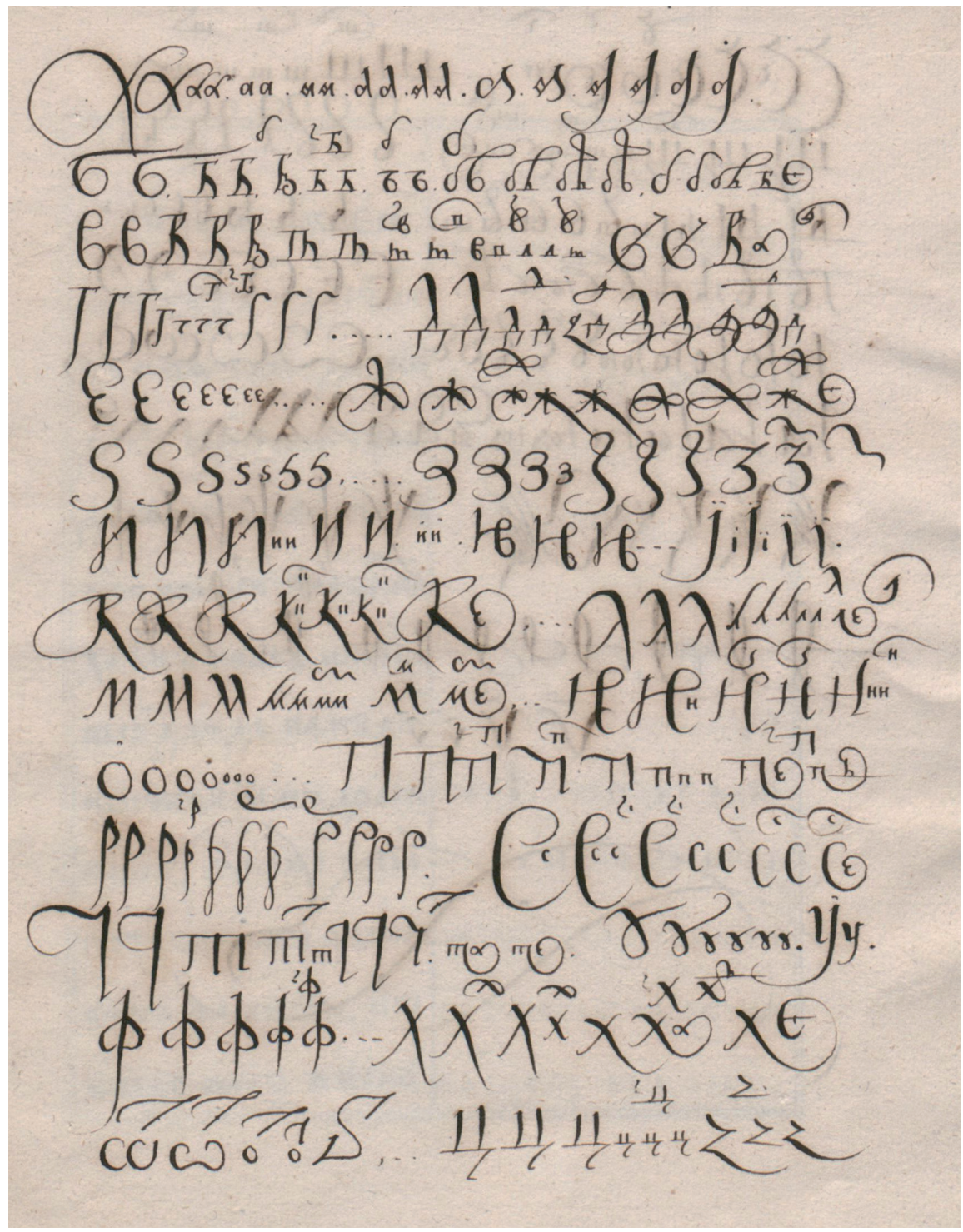

Abb. 2. Fol. [4]r: Die Buchstabenformen der Kanzleikursive, skoropis'(1. Teil)

tinkten Graphemen jeweils ein Punkt oder „...“ als Separator. Die vielen Entsprechungen des heutigen Graphems 〈я〉 (eine der interessantesten Zeilen in dieser Zusammenstellung) nehmen zusammen eine ganze Zeile ein, wobei der Eindruck erweckt wird, dass alle diese Formen - unter anderem auch die beiden 


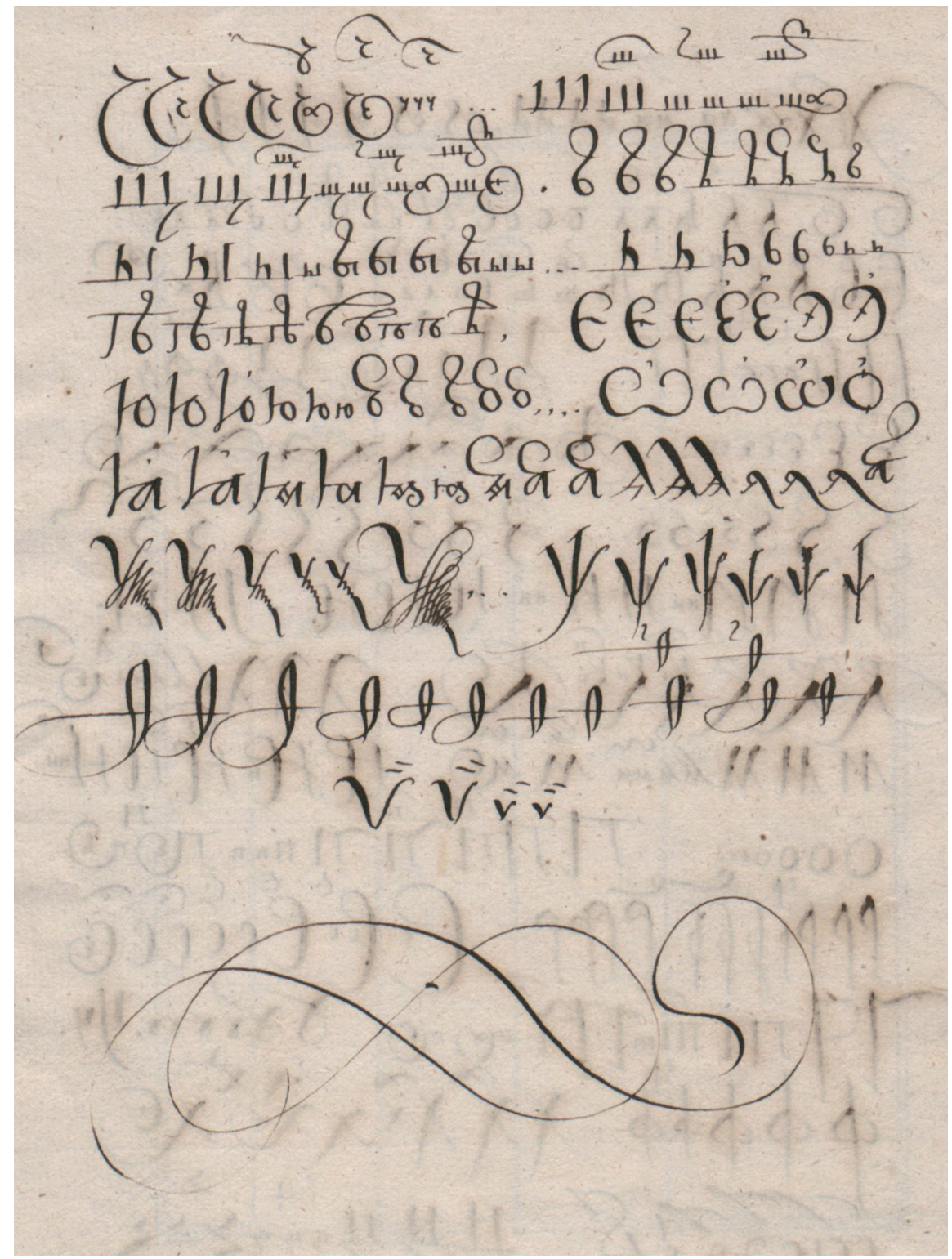

Abb. 3. Fol. [4]v: Die Buchstabenvarianten der Kanzleikursive (Forts.); unten Kotošichins charakteristischer Zier-Schnörkel.

„Dubletten“ 〈a〉 und 〈A〉, die ursprünglich auf verschiedene Grapheme zurückgehen - von unserem Schreiber als reine Varianten aufgefasst wurden, die 
teilweise mehr oder weniger kontinuierlich ineinander übergehen konnten; unter diesen Varianten ist auch die moderne Form 〈я〉. (Besonders schön wird dieser „Variantencharakter“ weiter unten in den Überschriften zu den Geboten 2-10 ${ }^{14}$ illustriert: Вторая, ТретьАя (in der gedruckten Vorlage: Третьаа), Четвертая, Пятал, ШестаА, Сед’маА, Осмая, ${ }^{15}$ Девятая, ДеслтаА; vgl. Abb. 4 für die Gebote 4-8.). Bemerkenswert ist außerdem, dass die Formen, die ihrem Ursprung nach auf ein und dasselbe Graphem zurückgehen, nicht konsequent zusammen gruppiert sind. So beginnt die Zeile mit zwei Formen eines ursprünglichen «a〉-Graphems (s. Abb. 3, Zeile 6), und auch das vierte und sechste Zeichen würde man wohl am ehesten als a jotirovannoe lesen, während dem dritten Zeichen sowie Nr. 5 und 7 offenbar sowohl Elemente aus a jotirovannoe als auch aus jus malyj zugrunde liegen - sie sehen alle aus wie Hybridformen aus den beiden ursprünglichen Graphemen. Die beiden folgenden Formen, 8 und 9, und auch die allerletzte, 16, können ebenfalls nicht leicht als eines der ursprünglichen Grapheme interpretiert werden (obwohl sie genetisch ziemlich sicher auf das «a〉 zurückgehen). Diese drei Formen werden in den Dokumenten des Posol'skij prikaz sehr häufig benutzt; heutige Herausgeber von skoropis'-Texten des 17. Jahrhunderts transkribieren sie normalerweise mit dem „modernen“ 〈я〉-Buchstaben. (Für diese Formen kennen wir selbst in unseren modernsten Computerzeichensätzen kein Zeichen. ${ }^{16}$ ) Danach kommt - in dreifacher Ausführung - ein Zeichen, das wir traditionell in unseren Editionen als 〈A〉 wiedergeben, dann ein eindeutiges modernes 〈я〉 (ebenfalls dreimal) und ganz am Ende noch eine weitere „undefinierbare“ und in unserer Typographie nicht reproduzierbare Form.

14 Das erste Gebot hat die Überschrift „а. 3“ (verkürzt für „первая заповедь“).

15 Die Form 〈O〉 hat A. Pennington (1980: 194) in Kotošichins Buch nicht registriert. In der Extranea-Handschrift wurde sie in die ausführliche Buchstabentabelle aufgenommen, und zwar zwischen $\langle\bar{k}\rangle$ und $\langle A\rangle$, mit der Entsprechung „ $\omega$ “ in der Spalte für die Namen der Buchstaben.

16 In Kotošichins Buch sind die Formen 8-9 - die sich ja nur minimal voneinander unterscheiden - sehr häufig vertreten; Beispiele findet man auf der „Titelseite“ seines Buches in Zeile 2 (боляры), 6 (для), 6-7 (8крьпления), 7 (времяни), 8 (взятыми) des Haupttextes; vgl. Abb. 6. In Anne Penningtons Ausgabe von Kotošichins Buch wurden diese Zeichen (und auch die Form Nr. 7) als 〈я〉 wiedergegeben, in der bisher letzten Ausgabe der Vesti-Kuranty jedoch als 〈a〉; vgl. Vesti-Kuranty 2009 und die Rezension von L. Sazonova zu dieser Ausgabe (Sazonova 2010). Irgendein Zeichen, das die Herausgeberin der einzigen existierenden philologischen Ausgabe von Kotošichins Hauptwerk als a jotirovannoe wiedergeben wollte, kam anscheinend im ganzen Buch gar nicht vor; 〈a〉 wird nur einmal erwähnt, und zwar im ersten Kapitel des Kommentarteils (Pennington 1980: 195). Im „Index der Formen“ kommt das Zeichen unter dem Buchstaben 〈я〉 nicht vor (ebd.: 749-751) - nicht einmal in Eigennamen wie Яковъ, Янка, Ярославль, die alle nur mit 〈A〉 geschrieben sind. 
Nach dieser „Einführung in die Paläographie“ (die Tabelle eignet sich auch heute noch hervorragend für alle, die Texte des Gesandtschaftsamts lesen und/ oder transkribieren wollen) folgen jetzt einige Katechismustexte, auf sechs Seiten, Fol. [5]r-[7]v; diese sind sicher als Lesestoff gedacht - als Übungstexte. (Das gedruckte Alfabetum hatte vor dem Katechismusteil noch drei Seiten mit sinnlosen Silben - ба ва га ..., бе ве ге ..., бла вла гла ..., бле вле гле ... -, entsprechend der Tradition der ostslavischen Fibeln; diese haben in der Handschrift gar keine Entsprechung.) Es handelt sich nur um einen geringen Teil der Texte, die in Alfabetum abgedruckt waren. Dessen Katechismusteil umfasste ganze 21 Seiten; in der Handschrift ist nur die „Haupttrias“ von Luthers Kleinem Katechismus - das Vaterunser, das Glaubensbekenntnis und der Dekalog - vertreten. (Das Manuskript behielt die recht ungewöhnliche Reihenfolge der Stücke aus der Vorlage bei. ${ }^{17}$ - Ausführlicher zu den Katechismustexten s. Abschnitt 4.3.) Typischerweise werden die Übungstexte in zwei verschiedenen Schriftarten dargeboten (denn die schwedischen Studenten mussten mit beiden vertraut sein): Die ersten dreieinhalb Seiten sind in Halbunziale geschrieben; in der Mitte von Fol. [7]v - nach dem Glaubensbekenntnis - erfolgt jedoch ein Wechsel zur Kanzleikursive, und der letzte der zitierten Katechismustexte (der Dekalog) ist jetzt in der kalligraphischen „Schnellschrift“ des Gesandtschaftsamtes ausgeführt.

Die letzte Textseite, Fol. [8]r, enthält die kyrillischen Buchstaben mit ihren Zahlenwerten, von 1 bis $1000000,{ }^{18}$ wobei nur die ersten Zahlen - bis 31 vollständig genannt werden, danach gibt es Kürzungen (z. B. „40, 41 usw.; 50, 51 usw.“). Das hier illustrierte Zählsystem unterscheidet sich von dem System, das traditionell in kyrillischen Handschriften verwendet wurde: Im traditionellen

17 Diese Reihenfolge entspricht nicht der traditionellen Anordnung in Luthers Katechismen, in denen der Dekalog an erster Stelle steht, danach das Glaubensbekenntnis und erst an dritter Stelle das Vaterunser (vgl. Albrecht 1915: 12; 39-40). Der Stockholmer Katechismus von 1628 - der seinerseits als Vorlage für Alfabetum diente (s. Maier 2012) - hatte die ursprüngliche, „Lutherische“ Reihenfolge; schon in Alfabetum wurde diese Ordnung jedoch geändert.

18 Aus der inneren Logik der Tabelle ergibt sich, dass das letzte Zeichen hier für eine Million steht (da es auf 900000 folgt); in einem anderen Zusammenhang wurde ein sehr ähnliches Zeichen offenbar als Bezeichnung für eine Milliarde verwendet, während eine Million durch das Zeichen (a) wiedergegeben wurde (vgl. Simonov 2000: 260-261). Ich nehme an, dass Zahlen über eine Million von nicht mathematisch geschulten Menschen leicht verwechselt wurden, wie das übrigens mit sehr hohen Zahlen auch heute noch der Fall ist, - in unserer Zeit werden zwar eine Million und eine Milliarde genau unterschieden, aber in den Größenordnungen der Billion und Trillion findet sich ein normaler Sprachbenutzer auch heutzutage nicht immer zurecht (vielleicht in diesem Fall vor allem, weil „Billion/billion“ heute im Deutschen und im Englischen nicht dasselbe bedeuten). 


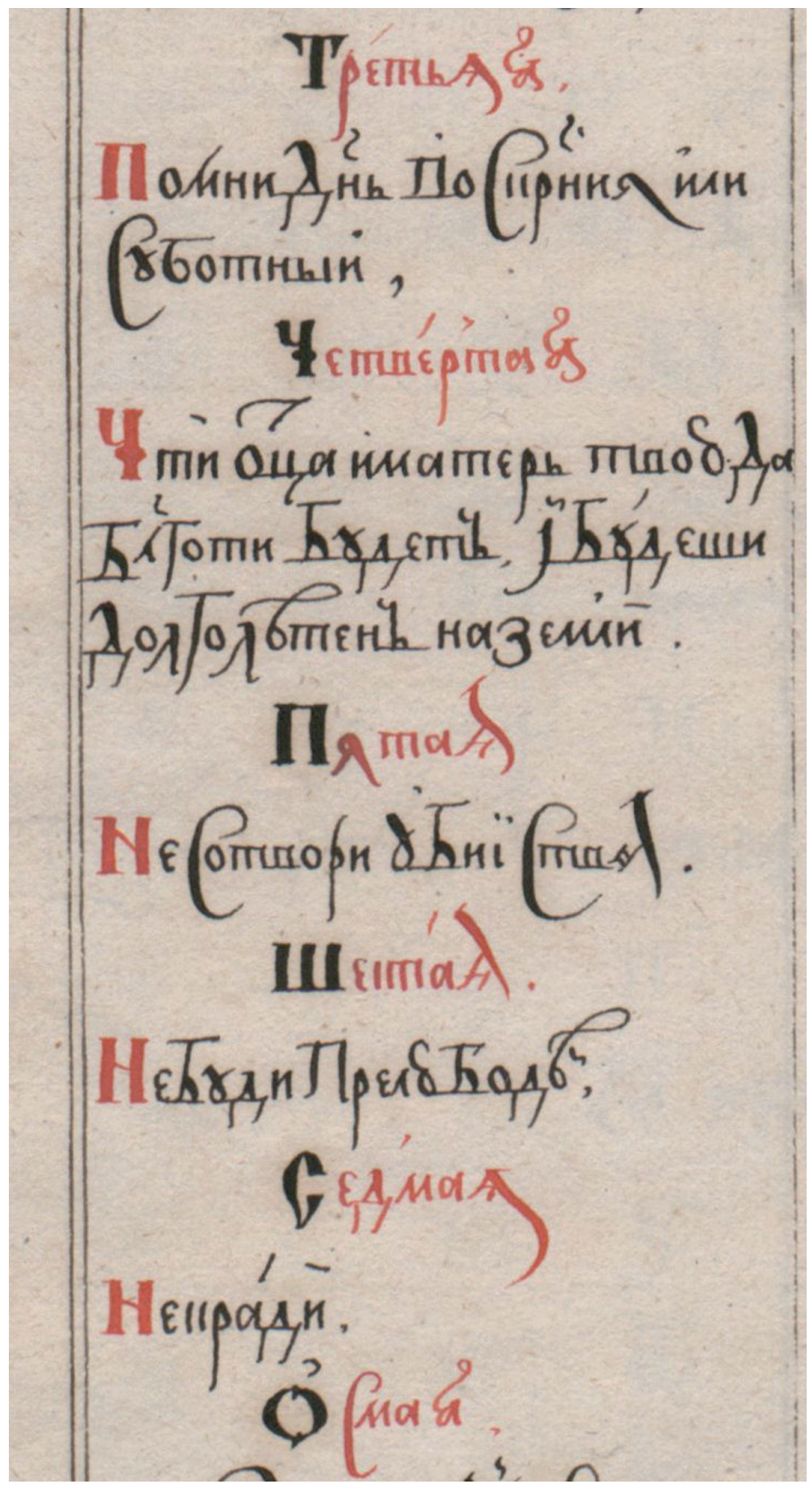

Abb. 4. Ausschnitt von Fol. [7]r: 3.-8. Gebot (s. besonders die verschiedenen Ausführungen des letzten Buchstaben in den sechs Überschriften). 
System wurden die Tausender nur bis einschließlich 9000 mit dem Symbol für „1000“ ( $\neq$, als Subscript) vor einer Zahl angegeben (z.B. „ $\neq 3$ “ für 7 000); die höheren Tausender dagegen - 10 000, 20 000, 30000 usw. - wurden mit den Zahlen für 1 (A), 2 (B), 3 (Г) usw. in einem Ring dargestellt, z. B. (a) für 10 000. Die nächste Zehnerpotenz - 100 000, 200000 usw. - bekam anstatt des durchgezogenen Rings einen durchbrochenen, punktierten; 1000000 usw. einen Ring aus „Strahlen“ (,$;) .{ }^{19}$ Unserer Handschrift liegt dagegen ein anderes Zählsystem zugrunde, nämlich dasjenige, das im Gesandtschaftsamt benutzt wurde: Hier wurden die Tausender konsequent mit dem Symbol „„““ (als Subscript) vor einer Zahl angegeben, und zwar auch nach 9 000; so wurde 10000 als „ÆI“ wiederge-

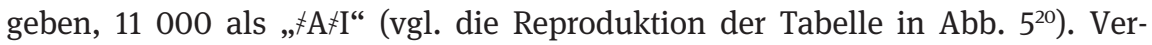
mutlich ist dieses System praktischer für hohe Zahlen - das Gesandtschaftsamt war ja genau der Ort, wo russische Schreiber regelmäßig mit sehr hohen Zahlen zu tun hatten, z.B. beim Herstellen der Vesti-Kuranty, Übersetzungen aus westeuropäischen gedruckten und geschriebenen Zeitungen, in denen ständig von enormen Armeen die Rede war, von Kriegsvorbereitungen und Schlachten mit Tausenden von Gefallenen und Gefangenen, aber auch Listen mit Waren, die aus Ostindien nach Holland importiert wurden, z. B. Riesenmengen an Stoffen, Zucker, Pfeffer, ungeschliffenen Diamanten usw.; ${ }^{21}$ bei großen zusammengesetzten Zahlen würden sich auch sehr unregelmäßige Zeilen ergeben, da manche Zahlen dann in einem Ring stehen, andere dagegen mit einem Subscript versehen wären. Die Tatsache, dass unser Schreiber das „Kanzleisystem“ verwendete, ist natürlich - neben der Kanzleischrift - ein weiterer Hinweis darauf, dass er eine Vergangenheit im Gesandtschaftsamt hatte.

19 Vgl. die Beispiele in Jagić 1968 [1896]: 639; Karskij 1928: 219; Ščepkin 1967: 151. Ein Beispiel für eine genau datierte Handschrift, in der das traditionelle System vertreten ist, ist das schon erwähnte niederdeutsch-russische Gesprächsbuch aus dem Jahre 1607; vgl. Fenne 1961: 557-559 (S. 559 enthält die hohen Werte, bis zu 1000 000). Allerdings wissen wir ja inzwischen, dass dem nach Fenne benannten Gesprächsbuch sehr viel ältere Vorlagen zugrunde lagen; vgl. neuerdings und sehr ausführlich Hendriks 2014. Bezüglich „mathematischer“ Argumente für wesentlich ältere Vorlagen s. Simonov 1977: 82-83.

20 Das einzige mir bekannte Lehrbuch, in dem dieses Zählsystem vertreten ist, ist das von Beljaev (1911: 61), das ja auch explizit zum Erlernen der Kanzleikursive gedacht ist.

21 Vgl. z. B. Vesti-Kuranty 2009: 111 (Schiffe, Kanonen und Kriegsvolk); 236-238 (Liste der Waren, die auf 12 Schiffen aus Ostindien nach Holland importiert wurden). 


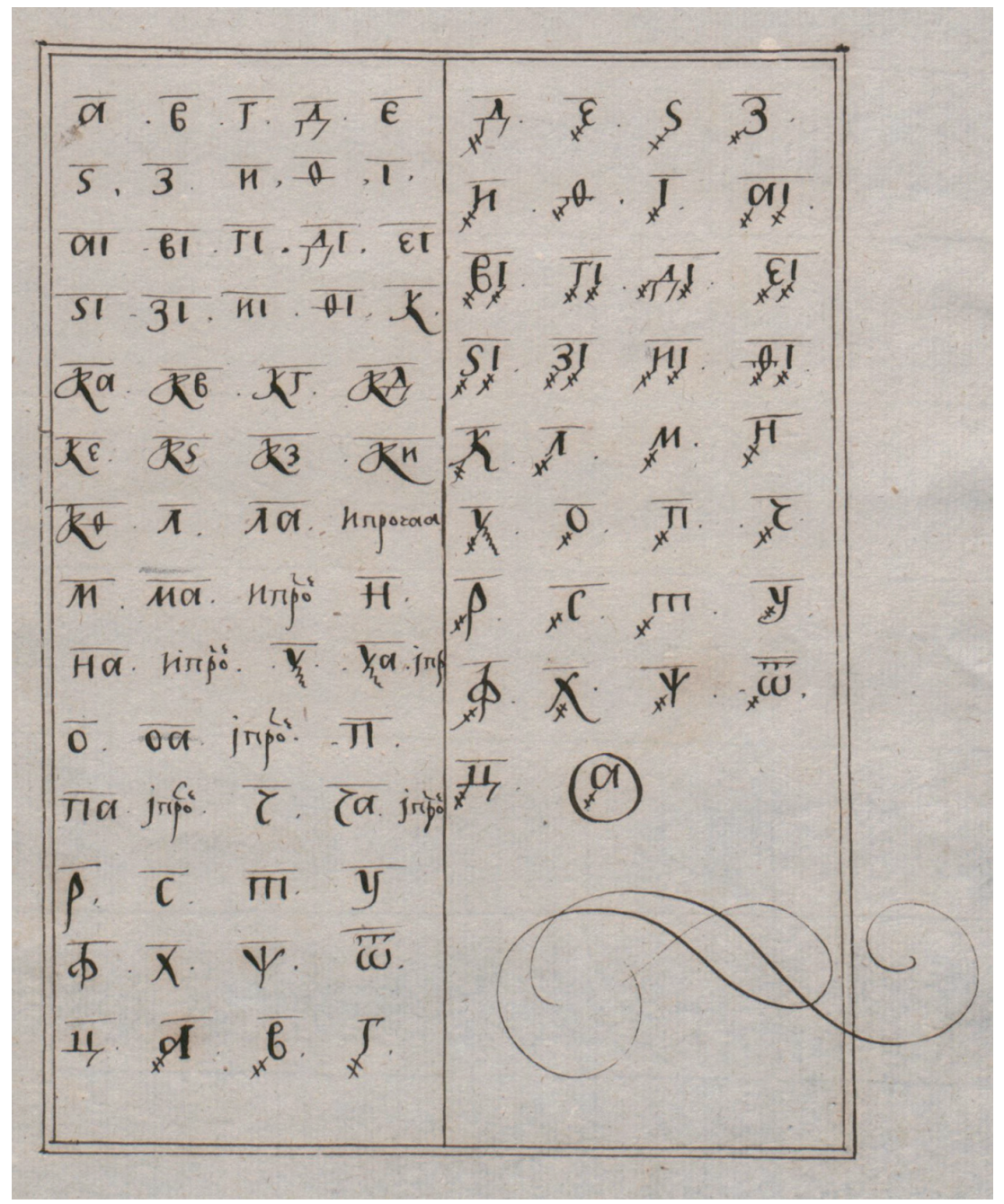

Abb. 5. Fol. [8]r: Mathematische Tabelle; am Ende der charakteristische Zier-Schnörkel (vgl. auch Abb. 3).

Die drei unbeschriebenen Seiten (Fol. [1]r-v und [8]v) und das Fehlen der schwedischen Texte im Katechismusteil weist meiner Meinung nach darauf hin, dass die als Lehrmittel gedachte Handschrift in der uns heute vorliegenden Form nicht vollendet war. Ich vermute, der Autor hatte vor, die leeren Seiten und Spalten später auszufüllen (bzw. von einem Kollegen ausfüllen zu lassen), wozu es aber nicht kommen sollte. 


\subsection{Zur Datierung der Handschrift}

Es kommt recht selten vor, dass ein undatierter Druck oder eine Handschrift auf Grund des Papiers - in erster Linie des Wasserzeichens - einigermaßen genau datiert werden kann. ${ }^{22}$ Dafür gibt es viele Gründe: Erstens ist nur ein Bruchteil aller jemals benutzten Wasserzeichen in wissenschaftlichen Arbeiten und Wasserzeichensammlungen erfasst (z. B. in gedruckten Verzeichnissen, online-Sammlungen usw.); zweitens wird der Wert vieler Abbildungen dadurch vermindert, dass die von den Bodendrähten des Schöpfsiebs verursachten Linien, die Kett- und Ripplinien, nicht in die Zeichnungen mit aufgenommen wurden. Wenn wir aber auf der Grundlage von Wasserzeichen die Entstehungszeit eines Papierbogens relativ genau beurteilen wollen, hilft es uns wenig, wenn wir ein ähnliches Zeichen auf einem datierten Papier finden, denn ein vom Typ her ähnliches Zeichen konnte selbstverständlich immer wieder von neuem hergestellt werden. Selbst ein im Grunde identisches Zeichen ist noch nicht ausreichend für eine zuverlässige Datierung, denn wenn ein Sieb ausgedient hatte, das Drahtzeichen - dessen Herstellung mit hohen Kosten verbunden war - aber noch intakt war, konnte dieses natürlich wieder in einem neuen Schöpfsieb befestigt und weiterhin verwendet werden, und das auch noch nach längerer Zeit (vgl. Gerardy 1964: 32; 1980: 38). Eine korrekte Datierung erhalten wir nur dann, wenn wir zeigen können, dass das zu datierende Papier in der gleichen Form hergestellt worden ist wie das schon datierte Papier, ${ }^{23}$ weshalb bei einem Papiervergleich und auf jeder Abzeichnung - Abpausung, Abreibung $^{24}$ - die Kett- und Ripplinien berücksichtigt werden sollten.

Mit dem Wasserzeichen in der Stockholmer Extranea-Handschrift hatte ich jedoch Glück. Auf Fol. [2] ist der obere Teil einer Narrenkappe mit fünf Schellen zu sehen; ${ }^{25}$ die „Fortsetzung“ davon (der untere Teil) ist auf Fol. [7]. Es gibt auch eine Gegenmarke, sogar dreimal, und zwar die Initialen „PHO“. Diese spezifische Narrenkappe mit der PHO-Gegenmarke wurde in der Literatur zur Papierfor-

22 Zur Problematik des Datierens mit Hilfe von Wasserzeichen siehe z.B. Gerardy 1964; 1969; 1980; Irigoin 1980; Stevenson 1967.

23 Vgl. Gerardy (1964: 31): „Seit Stevenson und Piccard ist es klar, daß zur Datierung nur identische Wasserzeichen[,] d.h. Wasserzeichen, die aus der gleichen Form stammen, miteinander verglichen werden dürfen. Kernproblem der Wasserzeichendatierung ist also, wie man mit einer alle Zweifel ausschließenden Sicherheit feststellt, ob ein Wasserzeichen in einem zu datierenden Papier mit einem datierten Wasserzeichen identisch ist oder nicht.“

$24 \mathrm{Zu}$ der letztgenannten Methode vgl. Haupt 1981.

25 Die Hauptmarke hat eine gewisse Ähnlichkeit mit Heawood (1950), Nr. 1944-1945 (aus dem Jahre 1677), Nr. 1986 (datiert 1680). Hier handelt es sich jedoch nur um ähnliche Typen; sie haben entweder andere Gegenmarken (Nr. 1944-1945) oder gar keine Gegenmarke (Nr. 1986), weshalb diese Marken für die Datierung unserer Handschrift wertlos sind. 
schung schon mehrmals behandelt: Zuerst hat sie F. Wibiral dokumentiert (Wibiral 1877: 167, Nr. 3k, aus dem Jahre 1669 oder etwas früher; Nr. 31, ungefähr 1670); später finden wir sie bei Laucevičius (1967, Nr. 2646, aus dem Jahre 1668), Rudén (1968, Anhang Nr. 27, aus den Jahren 1664-1668), Gaudriault (1995, Nr. 1020, datiert 1665) und Lindberg (1998, A 85, Nr. 418 aus dem Jahre 1668). ${ }^{26}$ Offenbar wurde dieses Papier in der Stockholmer Reichskanzlei in der zweiten Hälfte der 60er Jahre des 17. Jahrhunderts häufig verwendet, wie unter anderem auch aus der sehr sorgfältigen Studie von J. O. Rudén über die Narrenkappenwasserzeichen in der Düben-Musiksammlung ${ }^{27}$ hervorgeht (Rudén 1968), und tatsächlich stimmen mehrere von Rudéns Zeichnungen aus Musikhandschriften und Akten im Stockholmer Reichsarchiv genau mit dem Zeichen in unserer Extranea-Handschrift überein (einschließlich der Position der Kettlinien im Verhältnis zum Drahtzeichen). Auch generell bin ich weder in Wasserzeichenverzeichnissen noch in meinen eigenen Untersuchungen von datierten Akten im Stockholmer Reichsarchiv auf eine Narrenkappenmarke mit dem PHO-Gegenzeichen aus irgendeiner anderen Zeit als der Periode 1665-1673 gestoßen. Somit können wir schon jetzt festhalten, dass die hier behandelte Handschrift mit großer Sicherheit ebenfalls in dieser Zeit angefertigt wurde.

Wenn meine Argumente für Kotošichin als Verfertiger der Handschrift überzeugen (s. Abschnitt 3), können wir sie sogar noch genauer datieren, als das auf Grund einer Papieruntersuchung möglich ist: Sie entstand in diesem Fall zwischen Kotošichins Anstellung in Stockholm im Frühjahr 1666 und seiner Hinrichtung im November des darauffolgenden Jahres. Sogar eine noch genauere Datierung erscheint möglich: Die Narrenkappenmarke in der Extranea-Handschrift ist nämlich identisch mit einer der beiden Marken im zweiten Teil von Kotošichins Buch über den Moskauer Staat (Fol. 191-249; vgl. auch Pennington 1980: 8), das in der Universitätsbibliothek von Uppsala aufbewahrt wird. Wir können daraus schließen, dass er an dem Lehrmittel zur gleichen Zeit arbeitete, in der er auch die Reinschrift des letzten Teiles seines bedeutenden Buches anfertigte, oder sogar nach Beendigung des Buches. Deshalb kommt eher das Jahr 1667 in Frage, und da er diese Arbeit vermutlich nicht erst im Gefängnis erledigte, kann der Zeitraum noch weiter eingeschränkt werden, nämlich auf die Zeit vor dem 25 . August 1667 - dem Tag, an dem er im Gefängnis landete, da er seinen Kollegen und Hausherrn Daniel Anastasius in betrunkenem Zustand so gefährlich verletzt hatte, dass dieser ungefähr zwei Wochen später seinen schweren Wunden erlag.

26 Gaudriault (1995: 222) stellte fest, dass dieses Papier von dem französischen Papierfabrikanten Pierre Homo in Caen (Normandie) stammt; s. auch Lindberg (1998: A 179).

27 Diese Sammlung wird heutzutage in der Universitätsbibliothek von Uppsala aufbewahrt. 


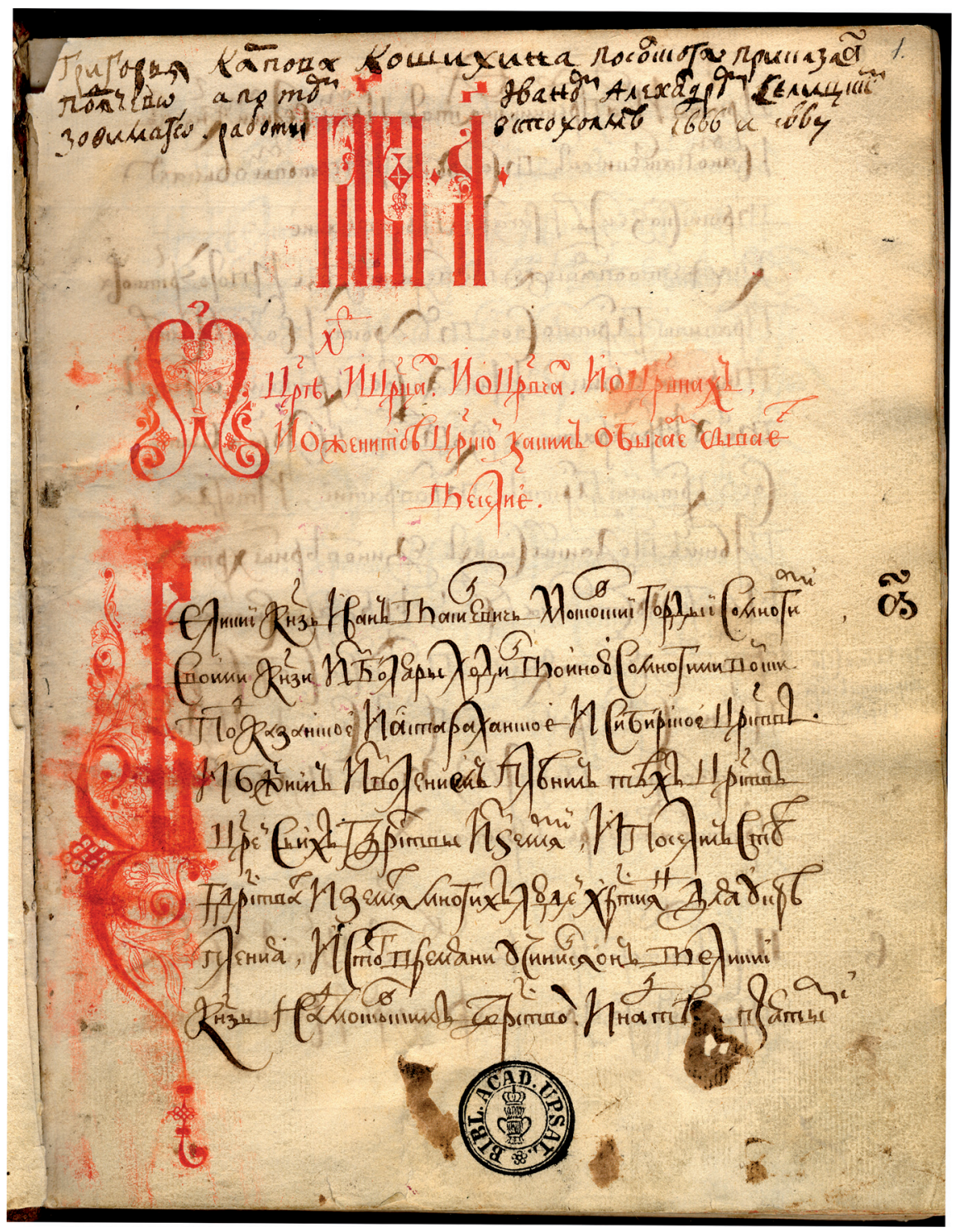

Abb. 6.Die Titelseite von Kotošichins Buch (Univ.-Bibl. Uppsala, Slav. 29). 


\section{Argumente für Grigorij Kotošichin als Verfertiger der Handschrift}

Schon am Anfang dieses Artikels habe ich erwähnt, dass die hier diskutierte Extranea-Handschrift meiner Meinung nach von Grigorij Kotošichins Hand stammt; hier sollen nun alle Argumente, die für diesen Verfasser sprechen, zusammengestellt werden. Ein Ausgangspunkt für alle Überlegungen ist die Tatsache, dass die Extranea-Handschrift allem Anschein nach in Schweden entstanden ist. Wollte man annehmen, sie sei in Russland entstanden, so müsste erstens nach dem Zweck gefragt werden (und wo ein dortiger Schreiber die gedruckte Alfabetum-Broschüre gefunden hätte); zweitens wäre es mehr als auffällig, dass in der gleichen Form geschöpftes Papier sowohl in der Stockholmer Kanzlei als auch in Russland verwendet wurde; drittens müsste dann erklärt werden, wie die Handschrift aus Russland ins schwedische Reichsarchiv gekommen sein kann.

Hier folgt nun die Aufzählung aller weiteren Argumente:

a) Nur eine Person mit einer Vergangenheit im Posol'skij prikaz war imstande, russische Texte nicht nur in Halbunziale, sondern auch in der kalligraphischen Kursive dieser Kanzlei zu schreiben; Kotošichin, der schon seit frühester Jugend in einer Moskauer Behörde arbeitete (und vom Jahreswechsel 1658-59 an bis zu seiner Flucht im Jahre 1664 im Posol'skij prikaz), ${ }^{28}$ beherrschte diese Schrift bis in die Fingerspitzen. Es fällt schwer, zu dem relevanten Zeitpunkt - 2. Hälfte der 1660er Jahre - auch nur eine weitere Person zu nennen mit einer Vergangenheit in der russischen Zentralverwaltung und den notwendigen Qualifikationen.

b) Nicht jeder beliebige Schreiber des Posol'skij prikaz hatte eine so perfekte Handschrift und konnte auch solche Initialen produzieren, wie das auf Fol. [2]r der Fall ist. Kotošichin war ein hervorragender Schreiber; nicht umsonst wurde gerade er im Jahre 1662 mit der ehrenvollen Aufgabe betraut, die Reinschrift eines Briefes an den schwedischen König anzufertigen: Am

28 Nach Dokumenten, die heute im Moskauer RGADA aufbewahrt werden, wurde Kotošichin kurz vor Weihnachten 1658 ins Gesandtschaftsamt (Posol'skij prikaz) überführt; unmittelbar davor war er als pod'jačij im „Großen Hof“ (Prikaz Bol’šogo dvorca) angestellt gewesen. Dies ist die früheste Erwähnung seines Namens in den auf uns gekommenen Akten (Belokurov 1906: 50, Anm. 2; vgl. auch Epstein 1978: 5 und Beljakov, im Druck). Es ist nicht ausgeschlossen, dass er in den Moskauer Behörden noch weitere Stationen durchlaufen hat, vor der „Endstation“ (Gesandtschaftsamt), wo er es ziemlich weit brachte. 
20. November 1662 wurden ihm für diese Reinschrift fünf Rubel ausbezahlt ${ }^{29}$ (das entsprach einem Viertel seines normalen Jahresgehaltes im Jahre 1662/ 63; Markevič 1895: 16; Beljakov, im Druck).

c) Das mathematische System auf Fol. [7]r der Handschrift weist ebenfalls auf eine Person aus dem Posol'skij prikaz hin; ein anderer Schreiber hätte eher das traditionelle - d.h. in älteren kyrillischen Handschriften gebräuchliche System verwendet (vgl. Ščepkin 1967: 151).

d) Wie oben schon gezeigt wurde (Abschnitt 2.2), wurde mindestens ein Blatt der Extranea-Handschrift und ein Teil der letzten ca. 60 Blätter von Kotošichins Buch im gleichen Schöpfsieb hergestellt. ${ }^{30}$ Mit einem Sieb wurden allerdings normalerweise ungefähr 300 000-400 000 Papierbogen produziert, bevor es ersetzt werden musste (Gerardy 1964: 63), so dass dieses

29 Vgl. RGADA, F. 137, Op. 1, Posol'skij prikaz, Nr. 1, Fol. 255r-v (über die Zeile geschriebene Buchstaben werden durch Kursivdruck wiedergegeben): „Ноября в К де по подписнои челобитнои за пометою думного дьяка Лариона Лопухина посолского приказу подячему Григорю Котошихину в приказ что он писал гсдрву грамоту к свиискому королю в лист пят рублев” (ich danke meinem ständigen Koautor S. Šamin für seinen hilfreichen Einsatz im Moskauer Archiv). Der entsprechende Zarenbrief selber wird in Stockholm aufbewahrt (RAS, Diplomatica Muscovitica, Vol. 618). Er enthält kein genaues Datum; der Text endet mit „¥3POA мца ноябрА ........... г днА “, d.h. das genaue Datum sollte später noch eingefügt werden, was aber hier - und übrigens auch in einigen anderen Fällen in diesem Aktenpaket - nicht geschehen ist. Aus den Briefen ist klar ersichtlich, dass die Reinschrift normalerweise im voraus hergestellt worden war, denn entweder fehlt der Tag ganz, so wie hier, oder er ist erst nachträglich (mit anderer Tinte) eingefügt worden, - manchmal nicht nur der Tag, sondern sogar auch der Monat! Einen anderen Zarenbrief aus dieser Zeit gibt es nicht, so dass wir mit Sicherheit annehmen dürfen, dass Kotošichin eben für diesen Brief sein zusätzliches „Honorar“ bekam. Auf der Rückseite des Briefes befindet sich ein „Empfangsvermerk“, auf Schwedisch: „Tzarens breff medh deß Påst Iwan Pieskow ankommit den 21 Januarij 1663, daterat Muschou den Nouembr: 7171 angående deß Legaters öfwersändande“ ('Brief des Zaren, angekommen mit seinem Kurier Iwan Pieskow am 21. Januar 1663, datiert Moskau den November 7171 [=1662], bezüglich Absenden seiner Legaten'). (Eine andere Bemerkung auf der Rückseite besagt, dass die Übersetzung im Januar 1666 aus dieser Akte entnommen wurde.) - Einige weitere Briefe des Zaren an den schwedischen König sind ziemlich sicher ebenfalls von Kotošichins Hand geschrieben, aber für alle anderen Fälle fehlt der direkte Beweis in Form eines Archivdokuments.

30 In den Papiermühlen wurden normalerweise zwei Schöpfformen gleichzeitig benutzt (Weiss 1962: 27), mit zwar sehr ähnlichen, jedoch nicht identischen Wasserzeichen (,Wasserzeichenpaare“, ebd.: 105-106; englisch twin marks, vgl. Stevenson 1952). Das ist der Grund dafür, dass meine Abpausung aus dem Schwedischen Reichsarchiv (nur eine Instanz des Hauptzeichens) nicht in allen Fällen identisch ist mit den Wasserzeichen auf den letzten Blättern von Kotošichins Buch; Übereinstimmung konnte nur für etwa die Hälfte aller Vorkommen festgestellt werden. Vgl. Fol. 218 in Kotošichins Buch als Beispiel für ein Blatt, das sicher im gleichen Sieb hergestellt wurde wie das Blatt mit dem Narrenkappenzeichen in dem handschriftlichen „Russischkompendium“ aus Stockholm. 
Argument - für sich allein genommen - wenig aussagekräftig wäre; zusammen mit allen anderen Argumenten ist es jedoch ein weiteres starkes Indiz, denn es ist dann ganz logisch, dass Kotošichin Papier aus der gleichen Lieferung ans „Archivum“ für seine Hauptaufgabe, das Buch, und die Nebenaufgabe (oder sein Privatvergnügen? - s. unten), das Russischlehrmittel, benutzte.

e) Ein genauer Vergleich der Handschrift in Kotošichins Buch und in der Extranea-Handschrift führt ebenfalls zum gleichen Ergebnis; es wäre fast ein Wunder, wenn zwei verschiedene Schreiber so ähnlich schreiben würden. Besonders deutlich wird die Ähnlichkeit bei den Zahlen (man vergleiche z. B. die Zahlentabelle auf Fol. [7]r der Extranea-Handschrift - Abb. 5 - mit den Zahlen im „Inhaltsverzeichnis“ von Kotošichins Buch auf Fol. 234-249), aber auch sonst können die meisten der Varianten aus Fol. [4] der Extranea-Handschrift auch in Kotošichins Buch belegt werden.

f) In Kotošichins Buch gibt es an einigen Stellen, wo der Text nicht die ganze Seite füllt, einen in einem Zug durchgezeichneten „Zierschnörkel“, meistens in der Form einer liegenden „8“ (s. vor allem auf Fol. 232v und 249v; diese Schnörkel sind natürlich niemals untereinander völlig identisch). Einen sehr ähnlichen Schnörkel finden wir auch an zwei Stellen in der Stockholmer Handschrift, und zwar auf Fol. [4]v und [8]r, d.h. am Ende der skoropis'Buchstaben und der Zahlentabelle (s. Abb. 3 und 5).

g) Die rote Zier-Initiale (,B“) auf der Titelseite von Kotošichins Buch ist in der Art und in der Ausführung sehr ähnlich wie die entsprechende - ebenfalls rote Initiale (,a“) der Stockholmer Handschrift: beide sind verziert mit Blumenund Blattmustern (vgl. Abb. 1 bzw. 6).

h) Die Orthographie in Kotošichins Buch und in der Stockholmer Handschrift ist verblüffend ähnlich. So wurde schon erwähnt, dass ein traditionelles 〈a〉-Graphem im Buch nicht vorkommt (s. Anm. 16); im „Russischkompendium“ gibt es zwar ein Vorkommen von «а〉, und zwar in dem Wort ако (auf Fol. [5]r) typischerweise jedoch in einem Text, der in Halbunziale geschrieben ist (auf der gleichen Seite finden wir ein Акоже, ebenfalls in Halbunziale). Aus dem letztgenannten Beispiel erkennt man leicht die Präferenz des Schreibers, denn in der gedruckten Vorlage war dieses Wort mit «a〉 geschrieben. In den skoropis'-Texten werden als Entsprechung für das heutige 〈я〉-Graphem nur diejenigen Formen verwendet, die A. Pennington in Kotošichins Buch registriert hat; vor allen Dingen kein a jotirovannoe, «a〉. Auch viele andere der von Pennington (1980: 190-196) genannten orthographischen Besonderheiten in Kotošichins Buch finden wir in den Zehn Geboten der Extranea-Handschrift dem einzigen in skoropis' geschriebenen Katechismustext (nur ungefähr zwei Spalten Text) - wieder: Die Grapheme « / ъ haben in beiden Handschriften 
immer deutlich distinkte Formen; in Kotošichins Buch dominiert « $४$ 〉 sehr stark gegenüber 〈y〉, während das letztgenannte Zeichen in der anderen Handschrift in dem kurzen skoropis'-Text gar nicht vorkommt; nach Vokalen steht für /j/ hier wie da immer ein hochgestelltes 〈И〉 (ungefähr in der Form eines liegenden „,“; ein 〈й〉 gibt es in keiner der beiden Handschriften); die Formen $\langle\varepsilon\rangle$ und 〈€〉 für das /e/-Phonem sind austauschbar (vgl. auf Fol. [6]v: заповєдєи, мєнє); in einer Kombination von zwei Graphemen für das /i/Phonem steht in Kotošichins Buch fast ausschließlich und in der Stockholmer Handschrift ausschließlich 〈иі〉, z. В. Бжиі ${ }^{31}$ (Fol. [6]v), 8биіства (Fol. [7]r; vgl. Abb. 4 im Fünften Gebot), übrigens ganz im Gegensatz zur kirchenslavischen Tradition, die hier «іи〉 hat. (Einige andere der von A. Pennington festgestellten orthographischen Charakteristika können wohl vor allem wegen der begrenzten Textmenge in der Stockholmer Handschrift nicht belegt werden.)

i) Die auffallende Abweichung in der „lateinischen Transkription“ des Graphems «3〉 (,Zemlja“) - in der gedruckten Vorlage „S“, in der Abschrift „,Z“ ist sehr leicht zu erklären, wenn Kotošichin der Schreiber war, denn mit seinem polnischen „Hintergrund“32 war es für ihn naheliegend, den russischen [z]-Laut in lateinischer Schrift mit einem ,z“ wiederzugeben.

Jeweils für sich genommen wäre jedes dieser Argumente nicht sehr aussagekräftig, aber alle zusammen ergeben sie doch ein sehr überzeugendes Bild: Ein anderer Schreiber als Kotošichin ist eigentlich undenkbar. In diesem Fall kann auch sehr leicht erklärt werden, wie diese Handschrift ins schwedische Reichsarchiv kam, denn weil Kotošichin seinen Arbeitsplatz in der staatlichen Kanzlei - und sogar im „Archivum“! - hatte, ist es nur natürlich, dass sein „Nachlass“ genau in diesem Archiv aufbewahrt wird. Wir können dann auch erklären, warum insbesondere die „schwedischen“ Spalten der Handschrift leer geblieben sind: Kotošichin hatte zwar im Frühling oder Sommer 1667 sicher einige Grundkenntnisse des Schwedischen, ${ }^{33}$ war aber offenbar noch nicht in der Lage, den in seiner Vorlage in Fraktur gedruckten schwedischen Text adäquat wiederzugeben. Entweder wollte er warten, bis er

31 Die Vorlage - das gedruckte Alfabetum - hatte an dieser Stelle Боӝ̈ (Fol. B1v), wodurch der Umstellung von «ï und 〈и〉 in der Handschrift ein noch größeres Gewicht zukommt.

32 Olof Barckhusen - Kotošichins Arbeitskollege und später der Übersetzer seines Buches berichtet in seiner Lebensbeschreibung über Grigorij Kotošichin („Vita Selitski“), dass dieser nur zwei Sprachen, Russisch und Polnisch, verstand („effter han annat måhl eij förstå kunde, än allenast Ryska och Pålniska"); s. Adde 1908: 3.

33 Davon zeugen ein paar schwedische Wörter in Kotošichins Buch, z.B. предіка für 'Predigt' und канна als Volumenmaß: „предіки не бывает“ (Fol. 30r; vgl. Pennington 1980: 35); „канна б8дет в два алтна“ (Fol. 112r; ibid.: 90); schwedisch predikan 'Predigt', kanna (ca. 2,6 1); vgl. auch Scheidegger (2004: 94). 
selber besser Schwedisch gelernt hat, oder es war seine Absicht, bei Gelegenheit einen Kollegen im Archiv um Hilfe zu bitten, z. B. den „Translator“ Olof Barckhusen oder den Dolmetscher Daniel Anastasius (bei dem er in Untermiete wohnte).

\section{Konsequenzen aus dieser Zuschreibung für unser Wissen um Kotošichin}

\subsection{Kotošichin als Russischlehrer in spe?}

Wie aus dem vorhergehenden Abschnitt hervorgeht, können wir mit großer Sicherheit davon ausgehen, dass das hier vorgestellte Lehrmittel von Kotošichin produziert wurde. Dagegen ist es schwieriger, die Frage zu beantworten, warum er das tat - war es seine eigene Initiative, oder wurde ihm diese Arbeit aufgetragen, als er mit seinem Hauptwerk fertig (oder jedenfalls fast fertig) war? Den Plan, dass er schwedischen Kindern und Jugendlichen die russische Sprache beibringen könnte, hatte er auf jeden Fall schon gleich nach seiner Ankunft in Schweden. ${ }^{34}$ Bereits im März 1666 richtete Kotošichin eine Petition an den - noch unmündigen - schwedischen König Karl XI. und eine weitere an den Reichsrat. ${ }^{35}$ Die erstgenannte Petition enthält keine spezifischen Vorschläge, womit er dem schwedischen Reich dienen könnte; in der zweiten aber macht Kotošichin recht konkrete Vorschläge: Man möge ihm doch einen schwedischen Studenten zuweisen, der ihm die schwedische Sprache beibringen könnte; im Gegenzug würde er diesem Studenten Russisch beibringen, so dass dieser Student anschließend als Russischdolmetscher dienen könne (Kotošichin war anscheinend ein früher Anhänger des heute so populären „Tandem-Systems“ zum Sprachenlernen). Außerdem bietet er an, schwedischen Kindern Russisch beizubringen - zumindest den Kindern der „Hohen Herren“ des Reichsrates (womit natürlich nur die Söhne gemeint sind), damit sie später entweder als Gouverneure dienen können in Gegenden, wo es von Vorteil ist, Russisch zu beherrschen, z.B. in Riga, oder als Abgesandte nach Russland geschickt werden können. ${ }^{36}$ Es entzieht sich meiner

34 H. Hjärne (1881: 63) nimmt an, dass Kotošichin am 5. Februar 1666 in Stockholm eintraf (gleichzeitig mit Generalgouverneur Jakob Johan Taubes Brief aus Narwa an den König vom 20.1., auf dem das Ankunftdatum verzeichnet ist).

35 Beide Petitionen sind unter anderem im Anhang von Penningtons Edition abgedruckt (Pennington 1980: 760-762; s. auch Grot 1882: 12-13, Anm. 1).

36 ,[...] и та моя служба его королевскому величеству будетъ годна такимъ обычаемъ: первое, чтобъ королевское величество пожаловалъ, велълъ меня учить свъйского языку 
Kenntnis, ob Kotošichin ein solcher Tandem-Student zugeteilt wurde und ob jemals ein schwedischer Jugendlicher in den Genuss kam, von diesem native speaker unterrichtet zu werden. Wie dem auch sei, er machte sich offenbar an die Arbeit, um ein geeignetes Lehrmittel herzustellen. Ob das auf seine eigene Initiative hin geschah oder auf Initiative seines Arbeitgebers, des schwedischen Staates, kann wohl nicht mehr mit Sicherheit herausgefunden werden. Einige Indizien sprechen meiner Meinung nach eher für die letztgenannte Alternative, unter anderem die Tatsache, dass das halbfertige Manuskript im schwedischen Archiv aufbewahrt wurde (wo es wohl nach Kotošichins Festnahme und Hinrichtung einfach liegen blieb) und dass es auf „staatseigenem“ Papier geschrieben war; außerdem konnte man ja für das ihm zugeteilte Stipendium von 300 Silbertalern pro Jahr (Hjärne 1881: 75, Anm. 1) etwas von ihm verlangen. Ich meine deshalb, er bekam von seinem Arbeitgeber den Auftrag, eine „Neuauflage“ von Alfabetum Rutenorum anzufertigen, und er bekam sicher auch die gedruckte Broschüre selbst, die als Vorlage dienen sollte. Für die Ausbildung von Russischdolmetschern der schwedischen Krone wurde zweifellos ein Lehrmittel benötigt, und die gedruckten Exemplare von Alfabetum waren vermutlich im Laufe der vergangenen Jahrzehnte aufgebraucht; außerdem enthielt das gedruckte Exemplar aus verständlichen Gründen keine Aufstellung der Buchstaben in den Formen der Kanzleikursive, und nicht einmal ein Verzeichnis der Zahlen - beide Elemente waren aber für zukünftige Dolmetscher und Übersetzer der schwedischen Krone unbedingt notwendig. (Eine Neuauflage der gedruckten Alfabetum-Broschüre war ausgeschlossen, da es seit Peter van Selow in Schweden keinen Drucker mehr gab, der kyrillische Typen - oder wenigstens Matrizen besaß.)

\subsection{Kotošichins Schwedischkenntnisse}

Wie wir aus der „Vita Selitski“ - der von Kotošichins Übersetzer, Olaf Barckhusen, verfassten kurzen Lebensbeschreibung - entnehmen können, verstand Kotošichin nur zwei Sprachen, Russisch und Polnisch (Adde 1908: 3; s. auch oben, Anm. 32). Bei den Gerichtsverhandlungen waren deshalb immer Dolmetscher

\footnotetext{
студенту, а я того студента буду учить по руски, что онъ годенъ будетъ въ переводчики; такъ же ежели похочетъ хто учитца по руски васъ высокихъ господъ дъти, и имъ то ученье будет надобно для такого способу: лучитца которому быть въ Ригъ или в иныхъ городъхъ губернаторомъ, и имъ для пограничества и для посолствъ годенъ будетъ [...]“ (zitiert nach Pennington 1980: 762; vgl. auch Markevič 1895: 38). Die ursprüngliche Handschrift existiert nicht mehr; alle Forscher reproduzieren eine vor langer Zeit gemachte Transkription.
} 
anwesend; der Pfarrer, Johann Herbinius, der den zum Tode Verurteilten öfter im Gefängnis besuchte, ihm mit Gottes Wort Trost schenkte und nach seinem Hinscheiden der Nachwelt bestätigte, dass er (Kotošichin) „obiit quam piissime“ (Hjärne 1881: 79-80), stammte aus Preußen und sprach gut polnisch. Der Wortwechsel und die Handgreiflichkeiten zwischen Kotošichin und Daniel Anastasius fanden auf Russisch statt. ${ }^{37}$ Das neue Manuskript fügt zu unserem bisherigen Wissen über Kotošichins Schwedischkenntnisse nichts Wesentliches hinzu, denn es war schon vorher bekannt, dass zumindest bescheidene (wahrscheinlich vor allem passive) Schwedischkenntnisse vorhanden waren. Die einzige neue Information in diesem Zusammenhang ist, dass Kotošichin anscheinend über das Verhältnis zwischen schwedischen Buchstaben und Sprachlauten einigermaßen informiert war (vgl. oben, Abschnitt 2.1).

\subsection{Kotošichin und die Religion}

Aus Olaf Barckhusens „Vita Selitski“ wissen wir, dass Kotošichin in Schweden zum Luthertum übergetreten war: „Die russische Religion gab er völlig auf und bekannte sich zu der lutherischen, denn er hielt die Russen, seine Landsleute, für ein blindes Volk, was die Religion betrifft [...]“; kurz vor seiner Enthauptung wurde ihm von Olof Petri Kråka das Abendmahl dargereicht. ${ }^{38}$ Auch die Bearbei-

37 In welcher Sprache Kotošichin mit Maria Fallentinsdotter, der Frau seines Hausherrn, sprach, entzieht sich meiner Kenntnis, und auch auf die Frage, ob es für die Eifersucht ihres Gatten einen reellen Grund gab, habe ich keine befriedigende Antwort. Das Gespräch zwischen Maria und Kotošichin, das einen Tag nach der Auseinandersetzung im Gefängnis stattfand, als ihr Mann noch am Leben war, hatte scheinbar einen recht komplizierten Inhalt; vgl. aus dem Verhandlungsprotokoll vom 10. September 1667 mit Frau Maria: „Gattin Maria erzählte auch, dass er am Tag danach, als sie bei Zeletski [= Kotošichin; IM] im Gefängnis war, zu ihr unter anderem gesagt habe, dass er sich selbst umgebracht hätte, wenn die Wache nicht so schnell gekommen wäre, um ihn festzunehmen “(,„S]edan refererade också hustru Maria, att andra dagen derefter, då hon till Zeletski uti corps de garde gick, hafver han bland allt annat sagt, att så framt vakten icke så snart kommit och honom antastat, skulle han sjelf hafva gjort af med sig“; zitiert nach Hjärne 1881: 76). Sehr unwahrscheinlich scheint mir, dass bei diesem Gespräch ein Dolmetscher anwesend war; es bleiben also zwei alternative Erklärungen übrig: Entweder konnte Kotošichin doch schon besser schwedisch, als wir bisher vermutet haben, oder Frau Maria Fallentinsdotter sprach - oder verstand - russisch. Am Tag der Auseinandersetzung, am 25. August, hatte er sich bei Kapitän Sven Göthe betrunken (ebd.: 78). Auch hier fehlen mir Angaben über mögliche fremdspachliche Kenntnisse dieses Kapitäns, aber die Gespräche erreichten ja bei diesem Anlass nicht unbedingt ein hohes theoretisches Niveau.

38 Barckhusens Originalwortlaut (zit. nach Adde 1908: 3): „Den Ryske Religionen öfwergaf han aldeles, och hölt sigh till den Lutherska idy han hölt Ryssarne, sine Landzmän för ett blindt Folk 
tung des katechetischen Materials in seinem Manuskript scheint zum Ausdruck zu bringen, dass es diesem Verfasser nicht gleichgültig war, was da stand; genau wie im linguistischen Teil folgte er auch hier durchaus nicht blind seiner Vorlage. Im Glaubensbekenntnis und in den Zehn Geboten machte er keine inhaltlichen Änderungen, aber das Vaterunser enthält - im Vergleich mit der Version in der gedruckten Broschüre Alfabetum - eine Ergänzung: In der Vorlage folgte auf die letzte Bitte des Gebetes unmittelbar das „Amen“; eine Entsprechung des Satzes „Denn dein ist das Reich und die Kraft und die Herrlichkeit in Ewigkeit“ fehlte in diesem Druck, sowohl auf Kirchenslavisch als auch auf Schwedisch.

Diese Doxologie (Lobpreisung) war in der Form des Gebetes, wie sie in Lukas (11,2-4) erscheint, nicht vorhanden; in der Version von Matthäus (6,9-13) ist sie mit variierendem Wortlaut - nur in relativ späten Handschriften enthalten. Luther hatte eine Form der Lobpreisung in seine deutsche Bibelübersetzung aufgenommen (Meyer 1929: 380), denn offenbar war sie in dem ihm vorliegenden griechischen Text vorhanden. In seinem Katechismus war sie dagegen $\mathrm{zu}$ seinen Lebzeiten nicht Bestandteil des Vaterunsers; erst nach seinem Tode wurde sie zum ersten Male in den Kleinen Katechismus integriert (ebd.). In den ältesten erhaltenen schwedischsprachigen Lutherischen Katechismen (gedruckt 1567 und - fast identisch - 1572) fehlte die Doxologie ebenfalls. ${ }^{39}$ Die früheste mir bekannte schwedische Katechismus-Ausgabe, die eine doxologische Formel enthält, ist die im Jahre 1620 bei I. Meurer in Stockholm gedruckte; ${ }^{40}$ in diesem Druck enthält das erste Vaterunser (ohne Luthers Erklärungen) den Satz „Ty Riket är titt/ Machten och härligheten i ewigheet/ [Amen]“ (Fol. A4r); in der Version des Gebets mit Luthers Erklärungen im gleichen Druck kommt jedoch nach der 7. Bitte, „Vthan frels oß ifrå Ondo“, direkt das „Amen“ (Fol. C3r-v). Auch in dem längeren russisch-kirchenslavischen Katechismus, der im Jahre 1628 bei Peter van Selow in Stockholm gedruckt worden war (und der seinerseits als Vorbild für Alfabetum diente; s. Maier 2012), war die Doxologie noch nicht enthalten. Ko-

uthi deras Religions wäsende; Effter han och något litet förr än han aflifwat blef, medh största andacht uthi fängelset undfick Herrans Högwerdiga Nattward, och den blef honom communicerat af en Swensk Cappelan, Wyrdige och Wällärde Hr Olof Petri Kråka, betienter uthi S:te Mariæ Kyrkia på Södre Malm.“

39 Der frühesten schwedischen Übersetzung lag offenbar vor allem die Wittenberger Ausgabe aus dem Jahre 1531 zugrunde; vgl. Lundström 1917: 173. (In dieser Ausgabe sind die Texte vieler früher schwedischer Katechismen abgedruckt, darunter auch der Ausgabe von 1572. Für die erste schwedische Ausgabe, 1567, vgl. Catechismus eller Christeligh kennedom 1916.)

40 UB Uppsala, Rar. 10:551. - In der lateinisch-schwedischen Ausgabe von 1635 (Strängnäs: Johannes L. Barkenius; UB Uppsala, Sv. avd. teol. katek.) ist die Doxologie schon in beiden Versionen des Vaterunsers enthalten: „Ty titt är Rijket/ och Machten och Herligheten j ewighet“ (Fol. A4r bzw. F2r, mit minimalen Unterschieden in den beiden Versionen). 
tošichin bricht nun mit dieser „Tradition“ der in Schweden produzierten kirchenslavischen Katechismen und fügt eine Version der Lobpreisung ein, und das ganz offenbar ohne irgendeine Vorlage, denn die doxologische Formel in unserer Handschrift ist recht ungewöhnlich (bei durch titlo abgekürzten Wörtern werden die ausgelassenen Buchstaben in Klammern ergänzt): „Ако твое есть ц(а)рство о(т)ца и с(ы)на и с(вя)таго д(у)ха. н(ы)нъ и присно и во въки въковъ“. Wenn unser Verfasser im linguistischen Teil seiner Lehrbuchnotizen neue Abschnitte einfügt, die in der Vorlage überhaupt keine Entsprechung hatten - nämlich die ausführliche Darstellung der skoropis'-Buchstaben oder die mathematische Tabelle - so kann das direkt durch den Zweck des Lehrmittels erklärt werden: Ein Übersetzer der schwedischen Krone, der die russische Kanzleikursive nicht lesen und die in den Zarenbriefen enthaltenen Zahlenangaben (auch Jahreszahlen) nicht korrekt wiedergeben kann, ist natürlich wertlos. Mit den Katechismustexten verhält es sich anders; sie sind in diesem Zusammenhang Illustrationen, Übungstexte. Was bringt unseren Schreiber dann dazu, auch an dieser Stelle von der Vorlage abzuweichen? Ich meine, wir können daraus schließen, dass er sich mit religiösen Fragen beschäftigte, dass er hellhörig war, was inhaltliche Unterschiede betraf. Vermutlich hat er bei einem Gottesdienst in Stockholm festgestellt, dass das Vaterunser, das dort gebetet wurde, ausführlicher war als die Version in Alfabetum; vielleicht besaß er sogar einen eigenen schwedischen Katechismus und falls dieser nicht allzu alt war, enthielt er mit Sicherheit ein Vaterunser mit der in Luthers Katechismen der Zeit gebräuchlichen doxologischen Formel. Als dritte Möglichkeit könnte einer von Kotošichins Arbeitskollegen entdeckt haben, dass das Vaterunser in Alfabetum nicht (mehr) die Version des Gebetes enthält, wie es in der Kirche gesprochen und in den Katechismen abgedruckt war; dieser Kollege könnte Kotošichin auf die Diskrepanz hingewiesen haben. Anscheinend erinnerte sich Kotošichin auch noch an eine ausführlichere Version, die er von Moskau her kannte. In einem russisch-orthodoxen Gottesdienst ist die Lobpreisung allerdings gar nicht Bestandteil des Vaterunsers (was einer der Gründe dafür sein könnte, dass er sich nicht genau erinnerte); nur das Gebet selbst wird von den Gottesdienstteilnehmern gemeinsam gesprochen, die doxologische Formel jedoch ausschließlich vom Priester, und so war es auch im 17. Jahrhundert. ${ }^{41}$ (In

41 Vgl. in Tolkovaja Biblija (1989: 128): „Но священник произносит после «Отче наш»: «яко Твое есть царство и сила и слава, Отца и Сына и Святаго Духа, ныне и присно и во веки веков»." Genau so lautet die Stelle auch im letzten vor Nikons Reformen gedruckten Moskauer Stundengebetbuch, das die feststehenden Teile der im Laufe eines Tageszyklus stattfindenen Gottesdienste enthält, mit Ausnahme der Göttlichen Liturgie (das Buch konnte sowohl in der Kirche als auch privat benutzt werden, d.h. zu Hause); vgl. Časoslov 1652, unter „Чинъ вечерни, и блгодаренїе в трапезъ на вечерАнїи“ (natürlich gibt es orthographische Abweichungen, und 
einem kirchenslavischen Gebetbuch für den Hausgebrauch enthielt das Vaterunser sowieso keine doxologische Formel, da sie eben nicht Teil des Gebetes war, sondern nur vom Priester gesprochen wurde.)

In der orthodoxen Liturgie gibt es mehrere doxologische Formeln, die einander alle irgendwie ähnlich sind und die selbst ein Priester leicht verwechseln kann, zumal sie in den handschriftlichen und sogar gedruckten Stundengebetsbüchern meistens gar nicht ausführlich zitiert werden, sondern - insbesondere im Falle der Doxologie nach dem Vaterunser - nur angedeutet, z.B. in der Form „Яко Твое есть Царство“; es wird vorausgesetzt, dass der Priester weiß, was er hier zu sagen hat. ${ }^{42}$ Kotošichin hatte aber offenbar kein Stundenbuch zur Verfügung, denn sonst hätte er eine andere Formel gefunden, zumindest bei der erstmaligen Anführung des Gebetes. In allen Quellen, in denen nach dem Vaterunser eine doxologische Formel genannt wird (wie z.B. in der Moskauer Bibel von $1663^{43}$ ) enthält diese - im Gegensatz zu unserer Handschrift - außer dem „Reich“ (царство) auch die „Kraft“ (сила) und die „Herrlichkeit“ (слава), genau wie alle modernen deutschen und schwedischen Versionen (in denen jedoch niemals die Dreieinigkeit genannt wird). In unserem Manuskript fehlt aber die „Kraft“ und die „Herrlichkeit“, während die Dreieinigkeit genannt ist, und gerade diese ungewöhnliche Kombination deutet auf einen Verfasser hin, der für seinen Einschub keinerlei schriftliche Vorlage zur Verfügung hatte. (In einem Gottesdienst in Moskau könnte er natürlich die Stelle unter Umständen einmal genau so gehört haben, wie sie hier zitiert wird - nämlich falls ein Moskauer Priester sich selbst auch nicht an den exakten Wortlaut genau derjenigen doxologischen Formel erinnerte, die er nach dem Vaterunser zu sprechen hatte.)

auch eine grammatische: въкшмъ). - Ich danke Dr. S. Poljanskij, Moskau (Vater Tichon) für seine hilfreichen Kommentare und viele Fotografien aus Časoslov 1652.

42 So wird z.B. in dem in Anm. 41 erwähnten Stundenbuch von 1652 bei jeder weiteren Erwähnung des Vaterunsers die vom Priester zu sprechende doxologische Formel jeweils nur angedeutet, vgl. z. В.: „ієрей глаголетъ возгласъ, юко твое есть црство“ (Časoslov 1652, Fol. на) - was keineswegs bedeutet, dass das Zitat auch wirklich in dieser verkürzten Form ausgesprochen werden sollte. Für die Form des Gebetes, wie sie von der Gemeinde gebetet wird - heute wie auch im 17. Jahrhundert, d.h. ohne die Doxologie - vgl. Molitvoslov (1915: 4). Eine doxologische Formel gibt es auch nicht im Vaterunser in dem nach T. Fenne/Fonne benannten Gesprächsbuch (vgl. Fenne 1961: 24).

43 In der Moskauer Bibel von 1663 lautete die entsprechende Stelle folgendermaßen: „яко твое есть царствие и сила и слава во вьки“ (aus Mt 6,13). Im Prinzip hätte sich in Stockholm wahrscheinlich ein Exemplar der Moskauer Bibel von 1663 auftreiben lassen, aber diese Frage ist nicht sehr relevant, da sie auf jeden Fall eine andere doxologische Formel enthält als unsere Handschrift. 
Auch dieses Detail passt hervorragend zu Kotošichin: Er komplettiert das Vaterunser seiner Vorlage (Alfabetum Rutenorum), aber nicht nach einer gedruckten kirchenslavischen Quelle - und erst recht nicht nach einer schwedischen, in der die Erwähnung der Dreieinigkeit an dieser Stelle undenkbar ist - sondern nach dem eigenen Gedächtnis. Sein Ziel wird wohl nicht gewesen sein, das Vaterunser so genau wie möglich nach der orthodoxen Gottesdienstordnung zu zitieren; im Gegenteil: Eher wird seine Absicht gewesen sein, das Gebet in der Form, in der es in Schweden in der Kirche gebetet wurde, auf Russisch wiederzugeben, also in einer Lutherischen Version, da er ja offenbar seinen orthodoxen Glauben in Schweden (oder auch schon in Polen) aufgegeben hatte. Diese „Anpassung“ ist ihm nun allerdings gar nicht gelungen.

$\mathrm{Zu}$ der Frage, wie aufrichtig Kotošichins Übertritt zum Luthertum war, oder ob es für diesen Schritt auch opportunistische Gründe gab (z. B. bessere Karrieremöglichkeiten in Schweden), ergibt sich aus dem neuen Dokument keine Antwort. Vielleicht könnte man auf Grund des inexakten Zitates in seinem Zusatz zum Vaterunser annehmen, dass er möglicherweise schon in Moskau nicht zu den engagiertesten Gottesdienstbesuchern gehört hatte, dass also die Religion in seinem Moskauer Leben keine ausgesprochen wichtige Rolle gespielt hatte.

\section{Abschließende Überlegungen}

In der vorliegenden Arbeit wurde eine Handschrift aus dem Stockholmer Reichsarchiv - ein „Russischkompendium“ oder Lehrbuchnotizen für schwedischsprachige Zielpersonen - beschrieben und auf die 2. Hälfte der 1660er Jahre datiert; es wurden auch eine Reihe Argumente angeführt, die zusammen genommen sehr stark dafür sprechen, dass diese Handschrift von Grigorij Kotošichin angefertigt wurde. Auf der Grundlage seiner Lebensdaten kann sie dann noch genauer datiert werden, nämlich auf die ersten acht Monate des Jahres 1667. Wir haben somit eine genau datierbare Schrift vor uns, die vor allem in den Teilen, die in der als Vorlage benutzten gedruckten Broschüre Alfabetum Rutenorum fehlten, sowohl für die russische Sprachgeschichte als auch für die Geschichte der Zahlzeichen von großer Bedeutung ist. Für die Sprachgeschichte ist insbesondere die Liste der Buchstaben in der Kanzleikursive sehr wichtig, denn so genau datierte Auflistungen, von denen uns sogar der Name des Schreibers bekannt ist, gibt es nur selten; außerdem ermöglicht uns dieses Verzeichnis einen gewissen Einblick in die subjektiven Vorstellungen des Schreibers bezüglich der Frage, welche der vielen verschiedenen Buchstabenformen von ihm als separate Grapheme und welche als Varianten betrachtet wurden. Dadurch ergeben sich einige interessante Schlussfolgerungen für die Gegenwart, unter anderem für unsere Ausgaben von sprachlichen Quellen 
aus dem letzten Drittel des 17. Jahrhunderts. Auf diese Problematik möchte ich jedoch in einem separaten Aufsatz noch einmal zurückkommen. Für unser Wissen um die Geschichte der Mathematik im Moskauer Staat des 17. Jahrhunderts ist die Handschrift nicht weniger relevant, denn auch hier fehlt es an Quellen, von denen wir genau wissen, wann, wo und von wem sie zusammengestellt worden sind. Ich habe vor, auch dieser Frage eine eigene Arbeit zu widmen. ${ }^{44}$

\section{Bibliographie}

Adde, G. (ed.) 1908. Beskrifning om Muschofsche Rijkets Staat, författat och schrifwin af een Rysk Cantzelist Grigori Carpofsson Cotossichin, förswänskat j Stockholm Anno 1669. Samtida skildring af 1600-talets ryska samfundslif. Stockholm: Ljus.

Albrecht, 0. 1915. Luthers Katechismen. Leipzig: Verein für Reformationsgeschichte (=Schriften des Vereins für Reformationsgeschichte; 121).

Beljaev, I. S. 1911. Praktičeskij kurs izučenija drevnej russkoj skoropisi dlja čtenija rukopisej $X V-X V I I I$ stoletij. Moskva: Sinodal'naja tipografija.

Beljakov, A. V. 2001. Služaščie Posol'skogo prikaza vtoroj treti XVII veka. Dis.... kand. ist. nauk. Moskva: RAN, Institut rossijskoj istorii [unveröffentlichte Dissertation].

Beljakov, A. V. Im Druck/2014. Žizn' Grigorija Kotošichina (po materialam Archiva Posol'skogo prikaza).

Belokurov, S. A. 1906. O posol'skom prikaze. Moskva: s.n.

Birgegård, U. 1992. Soobraženija o russkom jazyke v pis'mennom nasledii I. G. Sparvenfel'da. In Sjöberg, A./ Ďurovič, L./ Birgegård, U. (Hrsg), Dolomonosovskij period russkogo literaturnogo jazyka. The Pre-Lomonosov Period of the Russian Literary Language (Materialy konferencii na Fagerudde, 20-25 maja 1989 g.). Stockholm: Almqvist \& Wiksell International (= Slavica Suecana, Series B - Studies; 1), 41-60.

Buntašnyj vek. 1983. Buntašnyj vek. Vasilij Šukšin: Ja prišel dat' vam volju. Iz sočinenija Grigorija Kotošichina. Sostavlenie, predislovie, kommentarii V. S. Šul'gina. Moskva: Molodaja gvardija (=Istorija otečestva v romanach, povestjach, dokumentach. Vek XVII).

Časoslov. 1652. Časoslov. Moskva: Pečatnyj dvor.

Catechismus eller Christeligh kennedom. 1916. Catechismus eller Christeligh kennedom för vngt och eenfoldigt folck ganska nyttigh. Item een liten Bönebook (Stockholm 1567). Faksimil-

44 Dieser Artikel wurde verfasst im Rahmen des Forschungsprojekts Nr. RFP12-0055:1, das vom Jubiläumsfonds der Schwedischen Reichsbank finanziert wird. Ich danke B. A. Uspenskij, der es mir ermöglicht hat, die Resultate meiner Forschung im März 2014 in seinem Seminar linguistischsemiotischer Untersuchungen an der Vysšaja škola èkonomiki (Moskau) vorzustellen; den bei dem Vortrag anwesenden Kolleginnen und Kollegen danke ich für ihre anregenden Kommentare (insbesondere A. V. Lavrent'ev). Mein herzlicher Dank geht auch an meine Uppsalaer Kollegin Christine Watson, deren Kritik deutlich zur Verbesserung dieser Arbeit beigetragen hat. Winfried Schumacher (Köln) und Sabine Dumschat (Berlin) danke ich für stilistische Verbesserungsvorschläge, den beiden anonymen Gutachtern für die Korrektur einiger technischer Fehler. 
ausgabe: Den svenska katekesen 1567 i faksimile och med en efterskrift utgifven af Ragnar Dahlberg. Stockholm - Helsingfors: Lagerström.

Epstein, F. T. 1978. Die Hof- und Zentralverwaltung im Moskauer Staat und die Bedeutung von

G. K. Kotošichins zeitgenössischem Werk „Über Russland unter der Herrschaft des Zaren Aleksej Michajlovič“ für die russische Verwaltungsgeschichte. Hrsg. von Günther Specovius. Hamburg: Helmut Buske Verlag (=Hamburger historische Studien; 7).

Fenne, T. 1961. Tönnies Fenne's Low German Manual of Spoken Russian Pskov 1607. Ed. by

L. L. Hammerich, R. Jakobson et al. Vol. 1: Facsimile Copy. Copenhagen: Ejnar Munksgaard.

Gaudriault, R. 1995. Filigranes et autres caractérictiques des papiers fabriqués en France aux $X V I I^{e}$ et XVIII ${ }^{e}$ siècles. Paris: CNRS.

Gerardy, Th. 1964. Datieren mit Hilfe von Wasserzeichen, beispielhaft dargestellt an der Gesamtproduktion der Schaumburgischen Papiermühle Arensburg von 1604-1650. Bückeburg: Grimme (=Schaumburger Studien; 4).

Gerardy, Th. 1969. Identitätsbeweis bei der Wasserzeichenforschung. In Archiv für Geschichte des Buchwesens 9, 733-778.

Gerardy, Th. 1980. Die Beschreibung des in Manuskripten und Drucken vorkommenden Papiers. In Gruys, A. (Hrsg.), Codicologica. Les matériaux du livre manuscrit. Leiden: Brill (=Towards a science of handwritten books; 5), 37-51.

Grot, Ja. K. 1882. Novye svedenija o Kotošichine po švedskim istočnikam. Sanktpeterburg: Tipografija Imperatorskoj akademii nauk.

Haupt, W. 1981. Wasserzeichenwiedergabe in schwierigen Fällen. In Restauro 87, 38-43.

Heawood, E. 1950. Watermarks Mainly of the $17^{\text {th }}$ and $18^{\text {th }}$ Centuries. Hilversum: Paper Publications Society (=Monumenta Chartæ Papyraceæ Historiam Illustrantia; 1 ).

Hendriks, P. 2014. Innovation in tradition: Tönnies Fonne's Russian-German phrasebook (Pskov, 1607). Amsterdam/New York, N.Y.: Rodopi (=Studies in Slavic and General Linguistics; 41).

Hjärne, H. 1881. En rysk emigrant i Sverige för två hundra år sedan. In Historisk tidskrift 1, 53-84. Irigoin, J. 1980. La datation par les filigranes du papier. In Gruys, A. (Hrsg.), Codicologica. Les matériaux du livre manuscrit. Leiden: Brill (=Towards a science of handwritten books; 5), 9-36.

Jagić, V. 1968 [1896]. Codex Slovenicus rerum grammaticarum. Nachdruck des Separatdrucks Berlin 1896. München: Wilhelm Fink (=Slavische Propyläen; 25).

Karskij, E. F. 1928. Slavjanskaja kirillovskaja paleografija. Leningrad: Izdatel'stvo AN SSSR. Laucevičius, E. 1967. Popierius Lietuvoje XV-XVIII a. Vol. 1-2. Vilnius: Leidykla „Mintis“.

Łaszkiewicz, Hubert. 2007. pravivše gosudarstvo svoe ticho i blagopolučno... Grigorij Karpowicz Kotoszychin o władzy w Carstwie Moskiewskim pierwszych Romanowów. Lublin: Wydawnictwo KUL.

Leont'eva, G. A. 2000. G. K. Kotošichin. O Rossii v carstvovanie Alekseja Michajloviča. Podgotovka publikacii, vvodnaja stat'ja, kommentarii i slovnik professora G. A. Leont'evoj. Moskva: ROSSPĖN.

Lindberg, N. J. 1998. Paper Comes to the North. Sources and Trade Routes of Paper in the Baltic Sea Region 1350-1700. A Study Based on Watermark Research. Marburg/Lahn: IPH (=IPH Monograph; 2).

Lundström, H. 1917. Historisk-kritisk utredning angående Luthers Lilla katekes med särskild hänsyn till frågan om en svensk normaltexts framställande. Stockholm: Norstedt (=Meddelanden från Kungl. Katekesnämnden; 3).

Maier, I. 2012. Wer war der Autor von Alfabetum Rutenorum (Stockholm ohne Jahr)? In Podtergera, I. (Hrsg.), Schnittpunkt Slavistik. Ost und West im wissenschaftlichen Dialog. Festgabe für Helmut Keipert zum 70. Geburtstag. Teil 3. Bonn: Bonn University Press, 333-357. 
Markevič, A. I. 1895. Grigorij Kotošichin i ego sočinenie o moskovskom gosudarstve v polovine XVII veka. Odessa: Tipografija Štaba okruga.

Meyer, J. 1929. Historischer Kommentar zu Luthers Kleinem Katechismus. Gütersloh: C. Bertelsmann.

Molitvoslov. 1915. Molitvoslov. Petrograd: Sinodal'naja tipografija.

Pennington, A. (ed.). 1980. Kotošichin, G. O Rossii v carstvovanie Alekseja Mixajloviča: text and commentary A. E. Pennington. Oxford: Clarendon Press.

Rudén, J. 0. 1968. Vattenmärken och musikforskning: presentation och tillämpning av en dateringsmetod på musikalier i handskrift i Uppsala universitetsbiblioteks Dübensamling. Vol. 2 (Bilaga), Vattenmärken med motiv Narr i Uppsala universitets Dübensamling (1650-1690) [Licentiat-Dissertation, Universität Uppsala]. (Volltext online: http://www.ordommusik.se/ duben)

Sazonova, L. I. 2010. Rezension zu Vesti-Kuranty 2009. In Izvestija RAN. Serija literatury i jazyka. Tom 69, No. 4, 40-47.

Ščepkin, V. N. 1967. Russkaja paleografija. Moskva: Nauka.

Scheidegger, G. 2004. Emotions in the age of reason: Johann von Lilienthal and Grigorii Kotoshikhin, and their images of self and other. In Birgegård, U./Sandomirskaja, I. (Hrsg.), In search of an order: mutual representations in Sweden and Russia during the early Age of Reason. Huddinge: Södertörn Academic Studies, 85-96.

Simonov, R. A. 1977. Matematičeskaja mysl' Drevnej Rusi. Moskva: Nauka (=Serija Istorija nauki i techniki).

Simonov, R. A. 2000. Novye materialy po istorii matematiki Drevnej Rusi. In Istoriko-matematičeskie issledovanija. Vtoraja serija. Moskva: Janus-K, 244-271.

Stevenson, A. 1952. Watermarks are Twins. In Studies in Bibliography IV (1951-1952), 57-91.

Stevenson, A. 1967. The Problem of the Missale speciale. London: Bibliographical Society.

Šustova, Ju. Ė. 2010. Azbuka v pečatnych kirilličeskich bukvarjach južnoslavjanskoj i vostočnoslavjanskoj tradicii v XVI - načale XVIII v. In Kisterev, S. N. (Hrsg.), Očerki feodal'noj Rossii, Vyp. 14. Moskva - Sankt Peterburg: Al'jans-Archeo, 402-496.

Tarasov, V. 1997. G. K. K. Žizn' i neobyknovennye priključenija pod'jačego Posol'skogo prikaza. In Rodina 10, 55-59.

Tarkiainen, Kari.1974. Den tidiga kyrkliga slavistiken i Sverige. In Kyrkohistoriskårsskrift74,71-96.

Tolkovaja Biblija. 1989. Tolkovaja Biblija ili kommentarij na vse knigi Sv. Pisanija Vetchago $i$ Novago Zaveta (Red. A. P. Lopuchin). 3: Novyj zavet. 2-e izd. Stockholm: Institut perevoda Biblii [Nachdruck der Ausgabe Peterburg 1911-1913].

Uspenskij, B. A. 2013. Bukva é v drevnerusskich pevčeskich tekstach i v spiskach biblejskoj knigi Ischod. In Voprosy jazykoznanija 6, 79-114.

Uspenskij, B. A. 2014. Iz istorii slavjanskoj Biblii: Slavjano-evrejskie jazykovye kontakty v Drevnej Rusi (na materiale Nomina sacra). In Voprosy jazykoznanija 5, 24-55.

Vesti-Kuranty. 2009: Vesti-Kuranty 1656 g., 1660-1662 gg., 1664-1670 gg. Čast’ 1: Russkie teksty. Izdanie podgotovleno V. G. Dem'janovym pri učastii I. A. Kornilaevoj. Zaveršenie raboty nad izdaniem i podgotovka k pečati: E. A. Podšivalova, S. M. Šamin. Pod red. A. M. Moldovana i Ingrid Majer. Moskva: Rukopisnye pamjatniki Drevnej Rusi. (Volltext online: http://urn.kb.se/resolve?urn=urn:nbn:se:uu:diva-108287)

Weiss, K. Th. 1962. Handbuch der Wasserzeichenkunde. Bearbeitet und herausgegeben von Dr. W. Weiss. Leipzig: VEB Fachbuchverlag.

Wibiral, F. 1877. L'iconographie d'Antoine van Dyck d'après les recherches de H. Weber. Avec six planches, représentant de vieux filigranes. Leipzig: A. Danz. 